\title{
A tribute to the use of minimalistic spatially-implicit models of savanna vegetation dynamics to address broad spatial scales in spite of scarce data
}

\author{
Ivric Valaire Yatat Djeumen ${ }^{a, b}$, Alexis Tchuinté Tamen ${ }^{c, *}$, Yves Dumont ${ }^{a, d, e}$, Pierre Couteron ${ }^{c, f}$ \\ ${ }^{a}$ University of Pretoria, Department of Mathematics and Applied Mathematics, Pretoria, South Africa \\ ${ }^{b}$ University of Yaoundé 1, National Advanced School of Engineering, Yaoundé, Cameroon \\ ${ }^{c}$ IRD, Umr AMAP, Lmi DYCOFAC, Yaoundé, Cameroon \\ alexis.tchuinte@yahoo.fr; yatat.valaire@gmail.com; ivric.yatatdjeumen@up.ac.za \\ ${ }^{d}$ CIRAD, Umr AMAP, Pretoria, South Africa \\ ${ }^{e}$ AMAP, Université de Montpellier, CIRAD, CNRS, INRA, IRD, Montpellier, France \\ yves.dumont@cirad.fr; yves.dumont@up.ac.za \\ ${ }^{f}$ AMAP, IRD, Cirad, CNRS, INRA, Université de Montpellier, Montpellier, France \\ pierre.couteron@ird.fr \\ *The first two authors contributed equally
}

Received: 5 September 2018, accepted: 16 December 2018, published: 20 December 2018

\begin{abstract}
The savanna biome encompasses a variety of vegetation physiognomies that traduce complex dynamical responses of plants to the rainfall gradients leading from tropical forests to hot deserts. Such responses are shaped by interactions between woody and grassy plants that can be either direct, disturbance-mediated or both. There has been increasing evidence that several vegetation physiognomies, sometimes highly contrasted, may durably coexist under similar rainfall conditions suggesting multi-stability or at least not abrupt transitions. These fascinating questions have triggered burgeoning modelling efforts which have, however, not yet delivered an integrated picture liable to
\end{abstract}

furnish sensible predictions of potential vegetation at broad scales. In this paper, we will recall the key ecological processes and resulting vegetation dynamics that models should take into account. We will also present the main modelling options present in the literature and advocate the use of minimalistic models, capturing only the essential processes while retaining sufficient mathematical tractability and restricting themselves to a minimal set of parameters assessable from the overall literature.

Keywords-Biogeography; Rainfall; Fires; Ordinary differential equations; Impulsive differential equation; Tree-Grass interactions; Multi-stability.

Copyright: (C) 2018 Yatat Djeumen et al. This article is distributed under the terms of the Creative Commons Attribution License (CC BY 4.0) which permits unrestricted use, distribution, and reproduction in any medium, provided the original author and source are credited. 


\section{INTRODUCTION}

Savannas have been identified by biogeographers as a biome corresponding to warm mean annual temperatures $\left(>20^{\circ} \mathrm{C}\right)$ and a broad range of intermediate mean annual rainfall (100-2000 mm. $\mathrm{yr}^{-1}$ ) (Sarmiento (1984) [76], Youta Happi (1998) [114], Abbadie et al. (2006) [1], Lehmann et al. (2011) [58]). Such climatic context predominates along rainfall gradients leading from subequatorial wet climates to hot arid climates. The wider definition to which we refer here tends to integrate climatic variant allowing for nearly desert vegetation or on the contrary seasonal tropical forests. Savannas display specific interplays of natural constraints that prevent or at least impede closure of woody cover and ensuing suppression of light-demanding herbs and grasses. A central, albeit non-exclusive cause for this is the 'ideal fire climate' (Trollope (2011) [98]) that characterizes tropical regions with seasonal droughts alternating with warm and wet rainy seasons producing high herbaceous biomass that once dried-up becomes highly ignitable and fuels fires (Frost et al. (1986) [39], Thonicke et al. (2001) [93], Govender et al. (2006) [44]). High frequency of lightning storms which is a characteristic of Africa (Abbadie et al. (2006) [1], Trollope (2011) [98]) also contributes to make it the "Fire continent" even though present fire regimes mostly rely on human-made ignitions (Archibald et al. (2009) [7], Govender et al. (2006) [44], Trollope (2011) [98]).

Dynamics of vegetation within the savanna biome has long interested ecologists as it clearly departs from the classical post-disturbance succession pathways that are expected to rapidly bring back closed canopy forest, as observed in most of temperate and wet tropical climatic zones (Bond et al. (2005) [22]). The last decades have witnessed burgeoning efforts of modelling as to account for the possibly long-lasting coexistence of grassy and woody components and try to predict potential shifts from two-phased vegetation physiognomies. These efforts have, however, not yet delivered an integrated picture liable to furnish at broad scales (i.e., for fractions of continents) sensible predic- tions of possible vegetation dynamics. Such a big picture is nevertheless desirable for figuring out the future of vegetation in the face of climate and anthropic change scenarios (Mayaux et al. (2004) [60], Bond et al. (2005) [22], Archibald et al. (2009) [7], Accatino et al. (2010) [4], Favier et al. (2012) [36]). It is also necessary for applications to territories devoid of reference data and longterm observation sites, as it is the case for most of tropical Africa.

The objectives of the present contribution are fourfold. It first aims at recalling and synthetizing the main array of facts about ecological processes and resulting vegetation dynamics that models should aim to capture and render (see section II). Second, in order to claim genericity, we synthetize the main modelling options present in the literature, and put emphasis on minimalistic models, capturing only essential processes while retaining sufficient mathematical tractability and restricting themselves to a minimal set of assessable parameters (see section III). Thirdly, on this basis, we argue that such models have now become more comprehensive, and useful for meaningful predictions (see section IV). Finally, we discuss how those models may now help guiding data collection for improved calibration and testing of dynamical hypotheses (see section $\mathrm{V}$ ).

\section{A BRIEF REVIEW ON SPACE-IMPLICIT TREE-GRASS INTERACTIONS MODELLING}

\section{A. Tree-grass coexistence and possible alternative stable states}

Over very large tropical territories, field observers have documented long lasting coexistence of notable levels of grass and woody biomass (Backéus (1992) [9]). The most frequently reported form of coexistence is observed locally through vegetation physiognomies that associate fairly continuous grassy cover and more or less scattered populations of trees and shrubs of varying clumping levels. This is referred to as savanna physiognomy (see Figure 11). Such vegetation types mixing both lifeforms are manifold and progressively merge in space or through time 
without clear-cut boundaries (Torello-Raventos et al. (2013) [95]). Another modality of long lasting association between herbaceous and woody lifeforms occur at landscape scale under the form of mosaics featuring forests (usually closed canopy ones) and open savannas or grasslands (e.g. Figure 1. Bond and Parr (2010) [21]). In those landscapes that pertain to moist-wet climates, normally seen as favourable to forests, the mosaics appear highly contrasted and among the most "emblematic vegetation transitions" in the world (Oliveras and Malhi (2016) [72]): outside the closed forest, woody vegetation is of low biomass and the dominant physiognomies relate mainly to grassland. Moreover, boundaries between forest and grassland are generally sharp (Hoffmann et al. 2012 [48], CuniSanchez et al. (2016) [27]).

Our interpretations of those various physiognomies are limited by the length of the observation windows we can rely on for distinguishing trends against fluctuations. For field observations, this window length barely extend over some decades and this only for a very small number of sites where invaluable data have been gathered. At the scale of extensive territories, representativeness of those sites remains yet an open question. Remote sensing is progressively broadening our observational means. But the best nowadays space-borne sensors for estimating woody cover (Buccini and Hanan (2007) [26]) or biomass (Mermoz et al. (2014) [64], Bouvet et al. (2018) [24]) are recent and do not allow tracking changes far back. Moreover, the accuracy of those estimations, notably for woody cover is limited, due to the difficulty to separate grass vs. tree in signal responses in mixed stands. This is particularly true regarding long diachronic series that mainly feature optical images of insufficient spatial resolution. Apart from blatant changes, e.g., forest encroachment or recession, Mitchard and Flintrop (2013) [68], subtle evolution of the grass-tree balance in mixed physiognomies are still beyond reach. Remote sensing, however, recently brought two interesting contributions to the savanna debate. First, broad scale assessment of woody cover at regional (Central Africa, Favier et al. (2012) [36]) to continental/global scales (Hirota et al. (2011) [47]) clearly showed that contrasted levels of cover can coexist under the same ranges of climatic conditions, making the existence of multi-stable states at least plausible. Second, in both Central and West Africa, comparison between ancient air photographs from the $50 \mathrm{~s}$ and satellite images from the 80-90s frequently evidenced a progress of forest over savannas/grasslands in landscape featuring contrasted mosaics of the type exemplified in Figure 1] (Youta Happi (1998) [114], Mitchard et al. (2011) [69]).

Even though there is still no conclusive evidence that alternative stable states may exist within the savanna biome, models should be able to account for them as plausible outcomes of tree-grass interactions. The same applies to savanna physiognomies locally associating trees and grasses that may be seen as either stable or transient twophase states. Since those mixed physiognomies are observable at broad scale, there is no reason to a priori rule out that some observed mixtures may be stable under their local environmental context. Indeed, hypothesis testing is a fundamental role of models, though this use is not so widespread in ecology. And to this aim, the wider the array of reasonable predictions the more relevant is the model.

\section{B. Lines of thoughts}

Most authors agree on the fact that soil water budget, herbivory (i.e. grazing and/or browsing) and fires are the principal factors influencing growth of woody and herbaceous plants and their dynamical interactions (Scholes and Archer (1997) [79], Higgins et al. (2000) [45], Scholes (2003) [78], Van Langevelde et al. (2003) [101], Bond et al. (2005) [22], Bond (2008) [17], Abbadie et al. (2006) [1], Accatino et al. (2010) [4], Staver and Levin (2012) [84], Baudena et al. (2010) [11], (2014) [12], Jeffery et al. (2014) [51]). Authors however diverge on the relative importance of those factors in shaping dynamical outcomes of tree-grass interactions. This is not surprising considering the broad extent of the savanna biome 


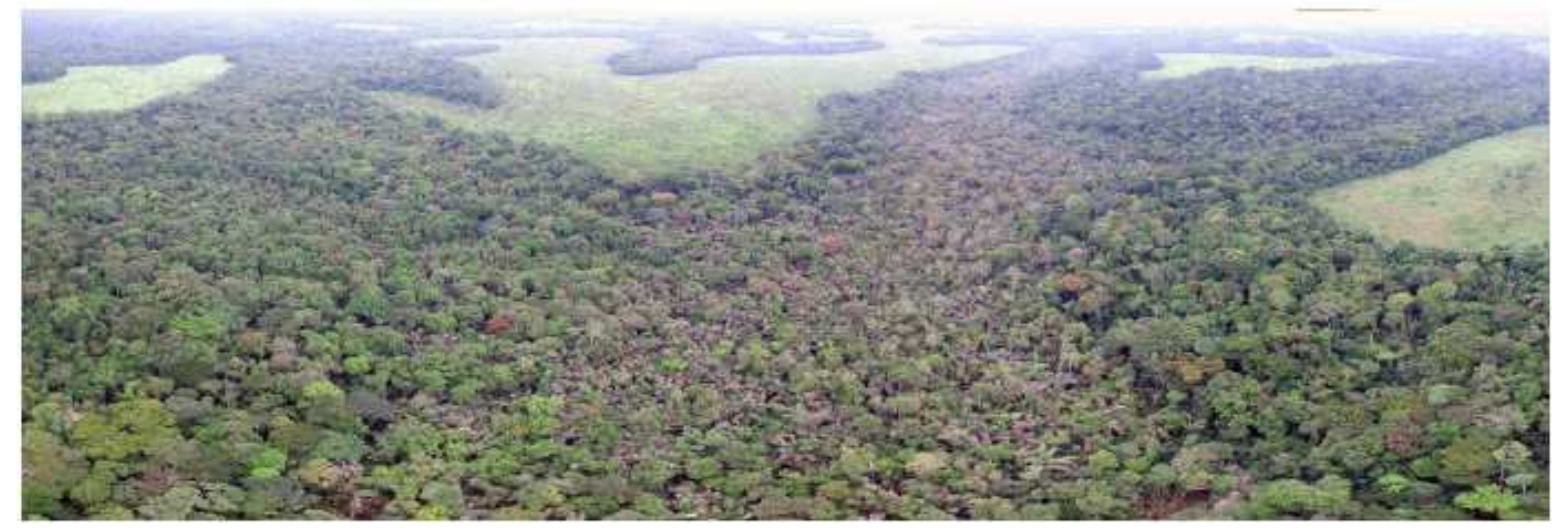

Figure 1: Landscape-scale mosaic between dense forest and herbaceous savanna (grassland) observed in central Cameroon (Ayos). Brownpink tree crowns indicate marshy forests in talwegs. Note the weak congruence between topography and the occurrences of forest vs. grassland. Airborne photo from N. Barbier, June 2017.

and the variety of both environmental conditions and anthropogenic pressures that apply therein. A factor appearing pervasive in a given context is not systematically due to prevail elsewhere. One group of authors has been insisting on direct interactions among or between plant-types (i.e. tree-tree or tree-grass) such as competition for light or for soil limiting resources (often moisture via root systems) (e.g. Scholes and Archer (1997) [79], Scholes (2003) [78]). It is obvious that the treegrass interaction is highly asymmetric: trees have a strong competitive effect on grasses, but grasses have a weak competitive effect on mature trees, although they may have a strong effect on saplings that have not grown above the grass layer (Scholes (2003) [78], Figure 2-a).

Another group of authors has been emphasizing that woody vegetation would be likely to reach a closed canopy situation and suppress grasses in the absence of recurrent disturbances induced by fires or browsers (or both sources) that delay or block the build-up of woody biomass by destroying the aerial part of seedlings and saplings (e.g. Bond et al. (2005) [22], Bond (2008) [17], Staver and Levin (2012) [84], Baudena et al. (2010) [11], (2014) [12], Jeffery et al. (2014) [51]; Figure 2. b \& -c). Browsers impact, though undoubtedly pervasive in certain situations (McNaughton and Georgiadis (1986) [62], Scholes and Walker (1993)
[80], Van Langevelde et al. (2003) [101], Holdo et al. (2009) [49]) is not systematic across the savanna biome and the generality of the disturbance hypothesis relies mainly on fire. Indeed, experimental fire suppression systematically leads to the thickening-up of the woody vegetation and to the development of dense woodlands or thickets. For sufficient annual rainfall, shifts toward close canopy forests are also observed (Bond et al. (2005) [22], Jeffery et al. (2014) [51]).

Literature may sometimes overemphasize the distinction between 'interaction' (between plant types for limited resource) and 'disturbance' hypotheses (see Scholes and Archer (1997) [79]) as to make them appear as alternatives, though they are by no means mutually exclusive. It is widely acknowledged that to have notable impact on vegetation, fire disturbance requests sufficient intensity through enough dry grass biomass as main source of fuel. Under a certain level of grass biomass, owing to insufficient rainfall or intense grazing, fires tend to spread difficultly and, where occurring, have modest impacts on woody plants. Logically, most authors tend now to distinguish disturbance-limited (i.e., under moist climate) vs. water limited (i.e., arid) savannas (e.g. Bond et al. (2003) [20]). Inter-tree competition shapes the second type (Sankaran et al. (2005) [75]), while asymmetric and fire-meditated tree- 

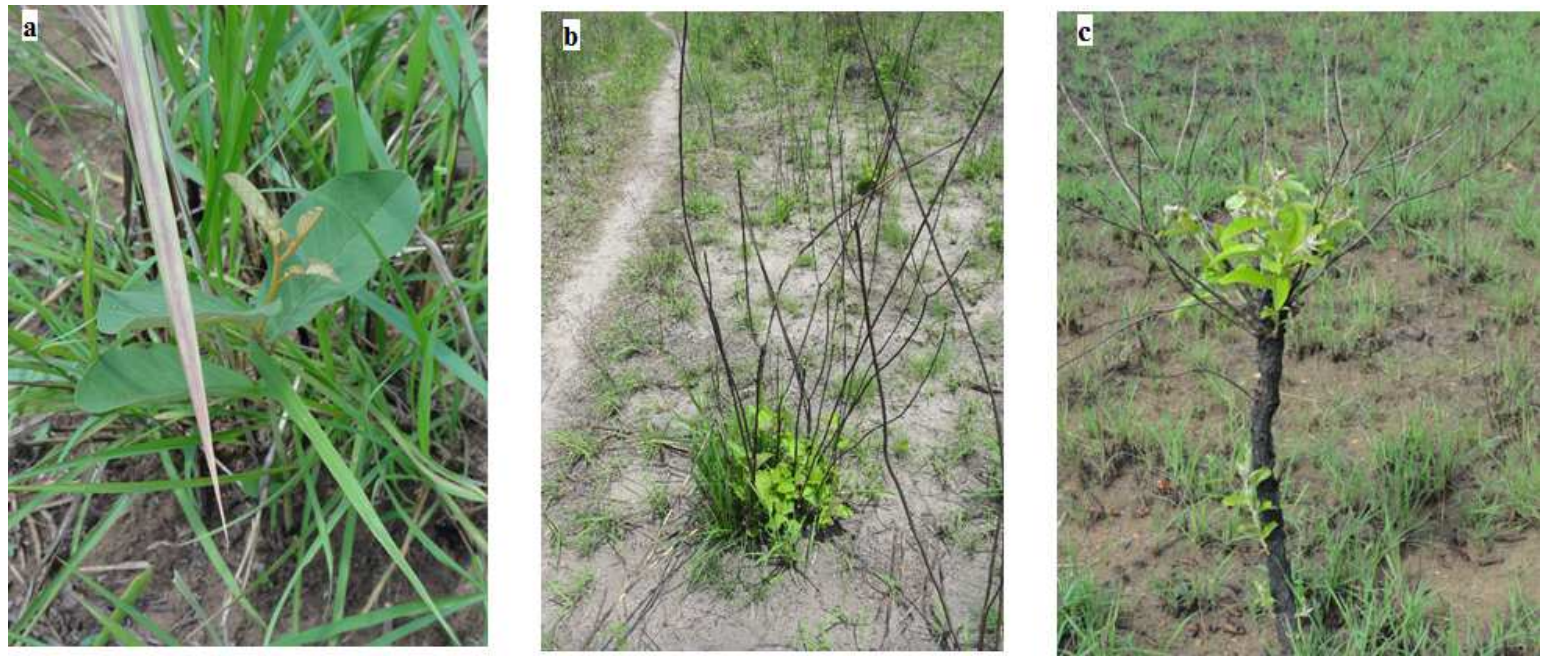

Figure 2: Three facets of woody plant resprouting just after fire and rainfall onset in the humid savannas of the Sanagha basin (Cameroon, Central Africa). Note that tufts of perennial grasses did also systematically resprout. Seedling struggling in a middle of a grass tuft a). Seedling resprouting after topkill either at ground b) or stem c) level. Photos: Pierre Couteron (March 2018).

grass interactions is central to the first one. But less clear-cut situations obviously occur under intermediate rainfall (Diouf et al. (2012) [31]) or because of modulation by edaphic conditions, grazing and anthropogenic pressures. Grazing may lead savannas toward physiognomies and functioning looking less fire-prone, i.e. more "arid-like", than expected from the only climate features as an emergent consequence of dynamical amplification of external forcing.

\section{MAIN PUBLISHED MODELLING OPTIONS}

The questions raised by observed or putative dynamics within the savanna biome have triggered an increasing interest in terms of modelling. Pioneering works (Walker et al. (1981) [103], Walker and Noy-Meir (1982) [104]) first used systems of ordinary differential equations (ODE) to address the particular case of arid, fire-immune savannas in which excessive grazing fosters bush encroachment (Skarpe (1990) [82]). This line of modelling featured grass and woody biomasses as state variables and aimed at explicitly depicting their interactions in relation to soil moisture dynamics. As such, it became a paradigm for 'interaction models' involving a limited resource, but the central assumption of soil niche partitioning between the two plant forms called Walter's (1971) hypothesis [105] has been ever since hotly debated and is obviously not verified in all ecological contexts where savannas, dry thickets or grasslands are observable.

Another line of ODE-based modelling built on the application to savannas of the initial concept of asymmetric competition of (Tilman (1994) [94]) through a simple framework that allows considering both direct and disturbance-mediated plant interactions. Tilman's framework reinterpretation (see Accatino et al. (2010) [4]), De Michele et al. (2011) [28] used two states variables, namely cover-fractions of grass $(G)$ and tree $(T)$ assumed exclusive and summing between zero and one. It modelled their interacting dynamics in a system of two ODE.

$$
\left\{\begin{array}{l}
\frac{d T}{d t}=c_{T} T(1-T)-\delta_{T} T, \\
\frac{d G}{d t}=c_{G} G(1-T-G)-c_{T} T G-\delta_{G} G,
\end{array}\right.
$$

where, $T$ and $G$ are dimensionless and denote the fractions of sites occupied by tree and grass 
respectively. $c_{T}$ and $c_{G}$ are the colonisation rates of tree and grass respectively. $\delta_{T}$ and $\delta_{G}$ represent the mortality rates of tree and grass respectively. In the sequel, we refer to system (1) as Tilman's model.

Logistic growth of the inferior competitor (grasses plus herbs) is bounded and depressed by the cover of the superior competitor (woody plants) which logistic growth is not directly affected by grasses (asymmetric competition). In system (1) there is no fire-mediated retroaction of $G$ on $T$. This was however introduced by subsequent authors (Van Langevelde et al. (2003) [101], Beckage et al. (2009) [14], Accatino et al. (2010) [4], Beckage et al. (2011) [13], De Michele et al. (2011) [28]) via a linear function of $G$. Thus, explicitly including the impact of fire on $T$ in Tilman's model, the first equation of (1) becomes:

$$
\frac{d T}{d t}=c_{T} T(1-T)-\delta_{T} T-\delta_{F} f \omega(G) T,
$$

where, $\delta_{F}$ represents the trees vulnerability to fire, $f$ is the fire frequency (inversely proportional to fire return time period) and $\omega(G)$ is a function of grass biomass that represents the fire impact. Through $\omega(G)$, there is thus indirect, fire-mediated negative feed-back of grass cover onto tree cover that counterbalance direct, tree-grass asymmetric interactions.

A larger array of models (see Tables I and II ) took a leaf from the previous modelling framework (system 1 and equation 2). Main sources of variations between models were: (1) nature of the equations and temporal treatment of fire disturbance (time-continuous forcing, i.e. ODE vs. time-discrete or impulsive occurrences); (2) nature of the function expressing grass-fire feedback on trees (linear vs. nonlinear); (3) integration of herbivory in addition to fire; (4) facultative explicit treatment of water availability through models with one (and sometimes more) additional state variables expressing water resource in interaction with vegetation variables. We will refer to such models as 'ecohydrological' (see Table II), among which is system (3) proposed by Accatino et al.
(2010) [4] that features a first equation devoted to the dynamics of a soil moisture variable $(S)$

$$
\left\{\begin{aligned}
\frac{d S}{d t}= & \frac{p}{w_{1}}(1-S)-\varepsilon S(1-T-G)-\tau_{T} S T \\
& -\tau_{G} S G \\
\frac{d T}{d t}= & c_{T} S T(1-T)-\delta_{T} T-\delta_{F} f T \omega(G), \\
\frac{d G}{d t}= & c_{G} S G(1-T-G)-c_{T} S T G-\delta_{G} G-f G
\end{aligned}\right.
$$

where $\frac{p}{w_{1}}$ (per year) represents the rainfall rate normalized with respect to root zone capacity, $\varepsilon$ (per year) is the evaporation, $\tau_{T}$ and $\tau_{G}$ (per year), are water uptake parameters for tree and grass respectively. $c_{T}, c_{G}, \delta_{T}, \delta_{G}, \delta_{F}$ and $f$ are defined as in system (1) and equation (2).

Note that setting $\omega(G)=0$ in the second equation of (3) makes Tilman's model (1) analogous to the system coupling the second and the third equations of (3). Moreover, if the $S$ variable is held constant, the main difference between systems (1) and (3) is that Accatino et al. (2010) [4] considered $\omega(G)=G$ (i.e., impact of fire on trees as a linear function of grass biomass) while in Tilman's model, this function is equal to zero (no impact of fire).

Taking $\omega(G)$ as any increasing function of the grass cover, provides a more general expression of the fire impact on trees. Without loss of generality, we referred to Holling type functions (Holling (1959) [50], Augier et al. (2010) [8], Tewa et al. (2013) [92], see equation (4) for generic ones). The general form of $\omega(G)$ reads as

$$
\omega(G)=\frac{G^{\theta}}{G^{\theta}+\alpha^{\theta}},
$$

where, $G$ in tons per hectare $\left(\mathrm{t}^{\mathrm{h}} \mathrm{h}^{-1}\right)$ is grass biomass, $\alpha$ is the value takes by $G$ when fire intensity is half its maximum, and the integer $\theta$ determines the steepness of the sigmoid. Nonlinear response was retained by some other authors (Scheiter and Higgins (2007) [77], Higgins et al. (2010) [46], Staver et al. (2011) [83], Touboul et 
al. (2018) [96]). Accatino and De Michele (2016) [3] also introduced a piecewise linear function of grass biomass (indeed qualitatively mimicking extreme non-linearity) in their non-equilibrium model (NEM) as the probability of the occurrence of fire.

Considering a nonlinear (sigmoidal) shape for $\omega(G)$ allows for the existence of up to three treegrass coexistence (i.e. savanna) equilibria, while two of them may be simultaneously stable (i.e. bistability) and forest-savanna-grassland tristability is reachable (Yatat et al. (2014) [112], (2018) [109], Tchuinté Tamen et al. (2014) [91], (2017b) [88]). Conversely, we proved that for linear $\omega(G)$ functions, tristability is unreachable (Yatat et al. (2018) [109], Tchuinté Tamen et al. (2018) [88]). As pointed out in Yatat et al. (2018) [109], possible tristability is in good agreement with results of Favier et al. (2012) [36] obtained along a general climatic transect over central African (latitude in the range of $3-4^{\circ}$ north). These results concerned a very large range of woody cover (wc) variations (from very low values approaching grassland physiognomies to nearly $80 \%$ cover (i.e. forest) through wc of $40 \%$, i.e. savanna) which suggests grassland/savanna/forest tristability as at least plausible. ODE models have been criticized on the basis that they only predict abrupt transitions between two alternative stable states (Accatino and De Michele (2016) [3]) that are deemed unrealistic. However, tristability of equilibria as well as bistability of two savanna equilibria suggests that shifts from one stable state to another may be less spectacular than hypothesized from previous models and that models may render more complex pathways of vegetation changes (see Yatat et al. (2018) [109] for further discussion).

In our earlier works (Yatat et al. (2014) [112], (2017) [110], (2018) [109], Tchuinté Tamen et al. (2014) [91], (2016) [89], (2017) [90]), we chose to use above-ground biomasses instead of covers as state variables in contrast to Accatino et al. (2010) [4] and most of the models which have been proposed on the subject (reinterpretation of Tilman (1994) [94], Baudena et al. (2010)
[11], Staver et al.(2011) [83], De Michele et al. (2011) [28], Synodinos et al. (2015) [85]) that considered cover fractions. Modelling biomasses help accounting from the fact that plant types are not mutually exclusive at a given point in space since field studies suggested that grass often develop under tree crowns (Belsky et al. (1989) [16], Belsky (1994) [15], Weltzin and Coughenour (1990) [107], Abbadie et al. (2006) [1], Dohn et al. (2012) [33], Moustakas et al. (2013) [70]). Moreover, biomasses directly refer to the cycle of carbon and can be assessed from radar remote sensing in savanna ecosystems that correspond to woody biomasses below the saturating level of the backscatter L-band radar signal (Mermoz et al. (2015) [65], Bouvet et al. (2018) [24]).

The minimal configuration of the published models (Tables II \& III) featured only two vegetation state variables (e.g., Van Langevelde et al. (2003) [101], Tchuinté Tamen et al. (2014) [91], (2016) [89], (2017) [90], (2017b) [88], Synodinos et al. (2018) [86]) as in Tilman's (1994) [94] initial framework, but several models distinguished size classes within the woody component of vegetation (e.g. Favier et al. (2004) [37], Baudena et al. (2010) [11], Staver et al. (2011) [83], Yatat et al. (2014) [112], (2017) [110], Touboul et al. (2018) [96]). Some models used more than two size classes through matrix population models (e.g. Accatino et al. (2013) [2], (2016) [5] and references therein). Simpler models used only two sizerelated variables in addition to grass and simply account for the asymmetric nature of tree-grass interactions as discussed previously (see also Scholes (2003) [78], Yatat et al. (2014) [112], (2017) [110]). Other models separate large trees, having top buds above the flame zone and therefore facing limited risks of topkill, from smaller trees and shrubs which have high probability of having their aerial systems destroyed (Beckage et al. (2009) [14], Staver et al. (2011) [83], Yatat et al. (2014) [112], (2017) [110]). This distinction stems from field observations (Trollope (1984) [97], Trollope and Trollope (1996) [99]) that evidence rapid decline of percent topkill with tree height (see 
I.V. Yatat Djeumen, A. Tchuinté Tamen, Y. Dumont, P. Couteron, A tribute to the use of minimalistic ...

Table I: Comparison of several models of tree-grass dynamics with respect to some modelling options. Walter's hypothesis refers to the differences in root depth of herbaceous and woody vegetation in water seeking while ecohydrological frameworks stand for models that consider additional state variables expressing water resource in interaction with vegetation variables. From Tchuinté Tamen (2017) [87] and Yatat (2018) [113]. The symbol * means that we refer to system (1)

\begin{tabular}{|c|c|c|c|c|c|c|c|}
\hline \multirow[t]{2}{*}{ Authors } & \multicolumn{2}{|c|}{$\begin{array}{c}\text { State } \\
\text { variables }\end{array}$} & \multicolumn{2}{|c|}{$\begin{array}{c}\text { Tree } \\
\text { state variables }\end{array}$} & \multirow{2}{*}{$\begin{array}{l}\text { Herbivory } \\
\text { perturbation }\end{array}$} & \multirow{2}{*}{$\begin{array}{c}\text { Walter's } \\
\text { hypothesis } \\
\text { applied }\end{array}$} & \multirow{2}{*}{$\begin{array}{c}\text { Ecohydro- } \\
\text { logical } \\
\text { frameworks }\end{array}$} \\
\hline & Cover & Biomass & All sizes lumped & Size-structured & & & \\
\hline Walker et al. (1981) [103] & & $\checkmark$ & $\checkmark$ & & $\checkmark$ & $\checkmark$ & \\
\hline Tilman $(1994)^{*}$ & $\checkmark$ & & $\checkmark$ & & & & \\
\hline Higgins et al. (2000) [45] & & $\checkmark$ & & $\checkmark$ & $\checkmark$ & & \\
\hline Van Langevelde et al. (2003)[101] & & $\checkmark$ & $\checkmark$ & & $\checkmark$ & $\checkmark$ & \\
\hline D’Odorico et al. (2006) [32] & $\checkmark$ & & $\checkmark$ & & & & \\
\hline Beckage et al. (2009) [14] & & $\checkmark$ & & $\checkmark$ & & & \\
\hline Baudena et al. (2010) [11] & $\checkmark$ & & & $\checkmark$ & & & \\
\hline Higgins et al. (2010) 46] & & $\checkmark$ & $\checkmark$ & & $\checkmark$ & & \\
\hline Accatino et al. (2010) [4] & $\checkmark$ & & $\checkmark$ & & & & $\checkmark$ \\
\hline De Michele et al. (2011) [28] & $\checkmark$ & & $\checkmark$ & & $\checkmark$ & & $\checkmark$ \\
\hline Staver et al. (2011) 83 & & $\checkmark$ & & $\checkmark$ & & & \\
\hline Beckage et al. (2011) [13] & & $\checkmark$ & $\checkmark$ & & & & \\
\hline Yu and D'Odorico (2014) 115 & $\checkmark$ & & $\checkmark$ & & & $\checkmark$ & $\checkmark$ \\
\hline Touboul et al. (2018) 96 & $\checkmark$ & & & $\checkmark$ & & & \\
\hline Synodinos et al. (2018) 86 & $\checkmark$ & & $\checkmark$ & & $\checkmark$ & & $\checkmark$ \\
\hline Yatat et al. (2014) [112] & & $\checkmark$ & & $\checkmark$ & $\checkmark$ & & \\
\hline Tchuinté Tamen et al. (2014) 91] & & $\checkmark$ & $\checkmark$ & & $\checkmark$ & & \\
\hline Tchuinté Tamen et al. (2016) & & $\checkmark$ & $\checkmark$ & & $\checkmark$ & & \\
\hline Tchuinté Tamen et al. (2017) [90] & & $\checkmark$ & $\checkmark$ & & $\checkmark$ & & \\
\hline Yatat et al. (2017) [110 & & $\checkmark$ & & $\checkmark$ & $\checkmark$ & & \\
\hline Yatat et al. (2018) [109 & & $\checkmark$ & $\checkmark$ & & $\checkmark$ & & \\
\hline Tchuinté Tamen et al. (2018) 88 & & $\checkmark$ & $\checkmark$ & & $\checkmark$ & & $\checkmark$ \\
\hline
\end{tabular}

also Figure 3). ODE models featuring two woody variables in addition to grass proved analytically tractable (Beckage et al. (2009) [14], Staver et al. (2011) [83], Yatat et al. (2014) [112], (2017) [110]) as long as other complexities were not introduced.

A strong objection against ODE models is that fire is not a forcing that continuously removes a small fraction of biomass through time as per the previous ODE equation systems. Instead, fire actually suppresses a substantial fraction of biomass at once through punctual outbreaks that shape ecosystem aspect and immediate post-fire functioning (Figure 4). This principle was implemented 
I.V. Yatat Djeumen, A. Tchuinté Tamen, Y. Dumont, P. Couteron, A tribute to the use of minimalistic ...

Table II: Summary of the characteristics of tree-grass interactions models with respect to fire modelling options (continued Table I]. From Tchuinté Tamen (2017) [87] and Yatat (2018) [113]. Some references (unticked) do not model fire. The symbol ${ }^{*}$ means that we refer to system (1).

\begin{tabular}{|c|c|c|c|c|c|c|}
\hline \multirow{2}{*}{ Authors } & \multicolumn{3}{|c|}{ Fire perturbation } & \multicolumn{2}{c|}{ Impact of Fire } \\
\hline & $\begin{array}{c}\text { time- } \\
\text { continuous }\end{array}$ & $\begin{array}{c}\text { time- } \\
\text { stochastic }\end{array}$ & $\begin{array}{c}\text { time- } \\
\text { discrete }\end{array}$ & $\begin{array}{c}\text { time- } \\
\text { impulsive }\end{array}$ & linear & $\begin{array}{c}\text { sigmoidal } \\
\text { forms }\end{array}$ \\
\hline \hline Walker et al. (1981) [103] & & & & & & \\
\hline Tilman (1994) [94] & & & & & & \\
\hline Higgins et al. (2000) [45] & & $\checkmark$ & & & & $\checkmark$ \\
\hline Van Langevelde et al. (2003) [101] & $\checkmark$ & & & & $\checkmark$ & \\
\hline D'Odorico et al. (2006) [32] & & $\checkmark$ & & & & \\
\hline Beckage et al. (2009) [14] & $\checkmark$ & & & & $\checkmark$ & \\
\hline Baudena et al. (2010) [11] & & $\checkmark$ & & & $\checkmark$ & \\
\hline Higgins et al. (2010) [46] & & & $\checkmark$ & & & $\checkmark$ \\
\hline Accatino et al. (2010) [4] & $\checkmark$ & & & & $\checkmark$ & \\
\hline De Michele et al. (2011) [28] & $\checkmark$ & & & & $\checkmark$ & \\
\hline Staver et al. (2011) [83] & $\checkmark$ & & & & & $\checkmark$ \\
\hline Beckage et al. (2011) [13] & & $\checkmark$ & & & $\checkmark$ & \\
\hline Yu and D'Odoricco (2014) [115] & $\checkmark$ & & & & & $\checkmark$ \\
\hline Touboul et al. (2018) [96] & $\checkmark$ & $\checkmark$ & & & & $\checkmark$ \\
\hline Synodinos et al. (2018) [86] & & $\checkmark$ & & & & $\checkmark$ \\
\hline \hline Yatat et al. (2014) [112] & $\checkmark$ & & & & & $\checkmark$ \\
\hline Tchuinté Tamen et al. (2014) [91] & $\checkmark$ & & & & & $\checkmark$ \\
\hline Tchuinté Tamen et al. (2016) [89] & & & & $\checkmark$ & & $\checkmark$ \\
\hline Tchuinté Tamen et al. (2017) [90] & & & & $\checkmark$ & & $\checkmark$ \\
\hline Yatat et al. (2017) [110] & & & & $\checkmark$ & & $\checkmark$ \\
\hline Yatat et al. (2018) [109] & & & & $\checkmark$ & & $\checkmark$ \\
\hline Tchuinté Tamen et al. (2018) [88] & $\checkmark$ & & & $\checkmark$ & & $\checkmark$ \\
\hline
\end{tabular}

via time-discrete recurrence equation models by Scheiter and Higgins (2007) [77], Higgins (2010) [46]. But another framework of impulsive differential equations (IDE) also proved relevant to gain realism regarding nature and consequences of fire while keeping a high level of analytical tractability thanks to the ODE modelling of inter-fires vegetation dynamics (Yatat et al. (2017) [110], Tchuinté Tamen et al. (2016) [89], (2017) [90]).

\section{REACHING SENSIBLE PREDICTIONS FROM MINIMAL MODELS}

A. A seminal "big picture" at biogeographic scale

The model from Accatino et al. (2010) [4] was pioneering and inspiring in that it first ventures into generically predicting vegetation physiognomies (in terms of percent covers of woody vs. herbaceous plants) over the entire savanna biome. The authors used bifurcation analysis (Accatino 


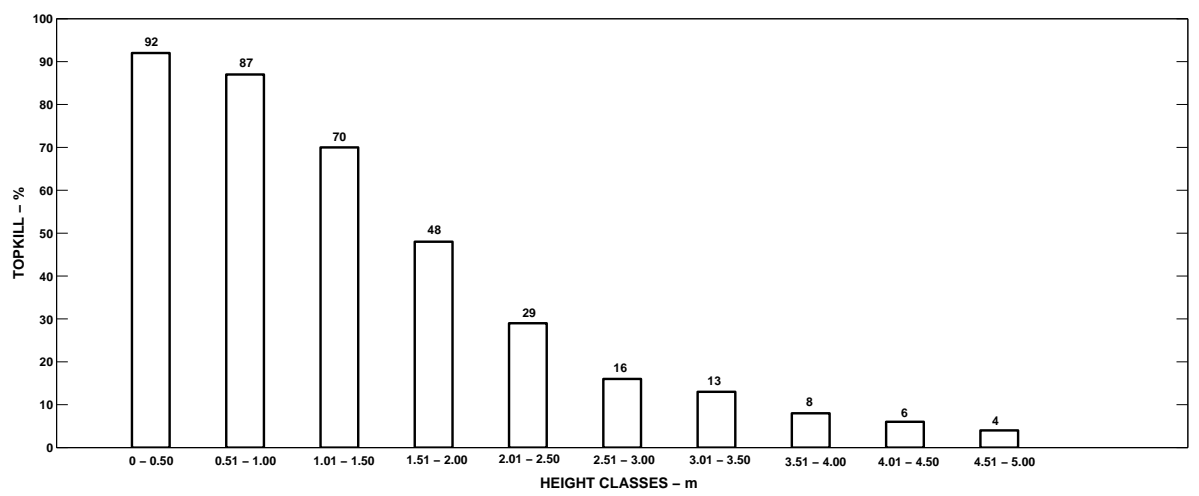

(a)

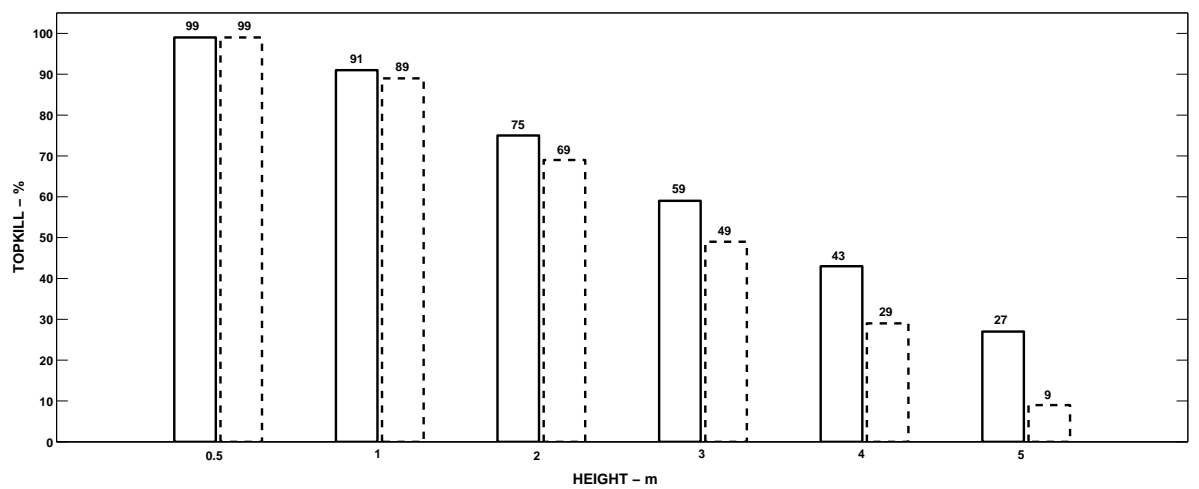

(b)

Figure 3: Illustration of the effect of height on the frequency of topkill of individual trees subjected to fires in the Kruger National Park (panel (a)) and in the central highlands of Kenya (panel (b)). In the panel (b), continuous bars denote head fire while black-dash bars represent back fire (reproduced from Trollope and Trollope (2010) [100], (C) Trollope and Trollope (2010) [100] ).
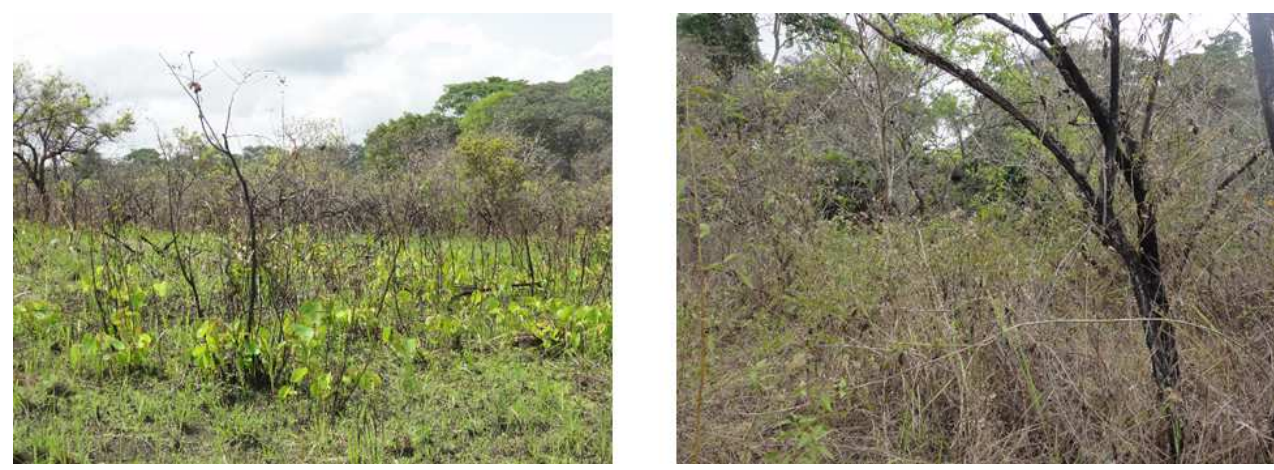

Figure 4: Aspects of two nearby savannas both located close to a forest boundary in the Sanagha Basin, Cameroon (Central Africa) depending on recent fire occurrence (left) or not (right). Photos were taken the same day. On the left, note the general resprouting of both the herbaceous stratum and topkilled woody plants. Photos: Pierre Couteron, March 2018. 
et al. (2010) [4], Tchuinté Tamen et al. (2018) [88], see also Figure 7) based on two important parameters of strong intuitive meaning, namely mean total annual rainfall and fire frequency. They thereby achieved delineation of domains in which main physiognomies (i.e., grassland, savanna, forest) can be expected as stable. Bistability situations (forest-grassland and forest-savanna) were also highlighted for sufficiently high fire frequencies. For low fire frequencies, a sensible gradient of increasing woody cover with increasing annual precipitation was found. But one may note that only dense woodlands (i.e. still two-phase vegetation) were obtained even for the highest rainfall range, while forest stricto -sensu (mono-phase, with no tall, light-demanding savanna grasses in the understory) is widely observed for the corresponding ranges of precipitations. Moreover, transitions between vegetation types in relation to fire frequencies proved tricky. Indeed, in the high rainfall range, increasing fire frequency leads from the aforementioned woodlands to forest. In the intermediate rainfall range, increasing fire frequency leads from savanna mono-stability to forest-savanna bistability (see Figure 7). Analogously, for fairly low rainfall, grassland stability shifts to grassland-forest bistability. Hence, all over the rainfall gradient it looks as if sufficient frequency of fire were a necessary condition to reach forest (bi)-stability. This is contradicted by empirical knowledge according to which frequent fires are known to jeopardize or at least delay woody biomass build-up, but never favour it (Bond et al. (2005) [22], Archibald et al. (2009) [7], Bond and Parr (2010) [21]).

Where did this critical problem come from? Most of subsequent papers barely evoked the question. A large share of them investigated different modelling options, often more complex and/or less tractable; or they assumed particular biogeographic conditions. In a further contribution, Accatino and De Michele (2016) [3] argued about intrinsic limitations of ODE-based modelling. They also put forward that there is no evidence according to which observed vegetation physiognomies may be close to a stable equilibrium point. It is in fact undisputable that climate is likely to vary through time, and there is no guaranty that woody vegetation can track such variation with enough celerity. They also underline as questionable the assumption according to which the parameter $f$ of fire frequency should be treated as a constant forcing, independently of vegetation characteristics. All these arguments brought them to propose a 'non-equilibrium model', based on stochastic difference equations, as alternative to the timecontinuous model of Accatino et al. (2010) [4] referred to as 'equilibrium-model' (EM). In their non-equilibrium (NEM) model, fire occurrence is a stochastic event all the more likely to occur in a given dry season that ignitable dry grass biomass abundantly built-up in the foregone rainy seasons.

Accatino and De Michele (2016) [3] compared the predictions of their (EM) vs. (NEM) models. They argued that separation of fire-immune vs. fire-prone savannas as an indirect consequence of rainfall is an emergent property with their NEM while it is artificially induced by the choice of the $f$ parameter with EM. They also pointed out that when considering high rainfall, the NEM is able to reproduce the "bimodality" of woody cover extent observed in remote sensing studies. But in fact, their NEM was not a straightforward time-discrete analogue of the ODE based EM of Accatino et al. (2010) [4], since it features several novelties. Therefore, the differences they reported between EM and NEM are not a simple consequence of time-continuous fire forcing vs. time-discrete fire occurrences. In fact, several aspects altogether contribute to the more satisfactory results obtained with the NEM by Accatino and De Michele (2016) [3]. We will subsequently illustrate the fact that predictions that are qualitatively satisfactory can be obtained by directly improving the ODE based 'EM' framework, notably regarding the firemediated feedback of grass onto tree dynamics.

\section{B. Fire frequency, grass biomass and fire impact}

The way in which fire impact is modelled in the previous equation systems 1 and 3 is obviously a crucial question. As stated by Scholes (2003) 


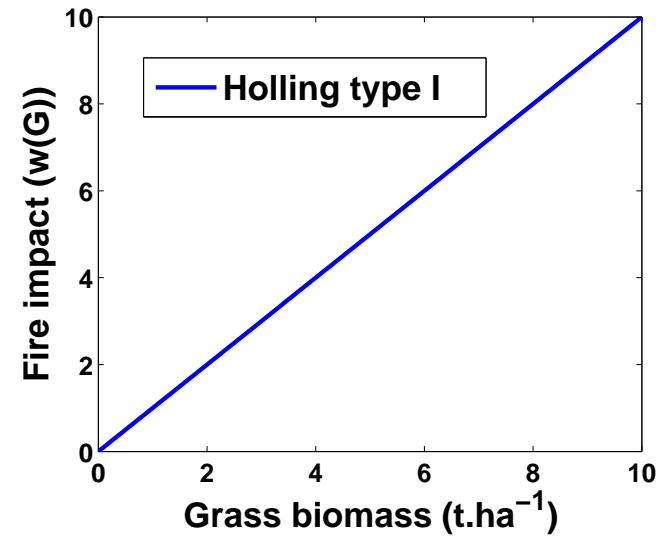

(a)

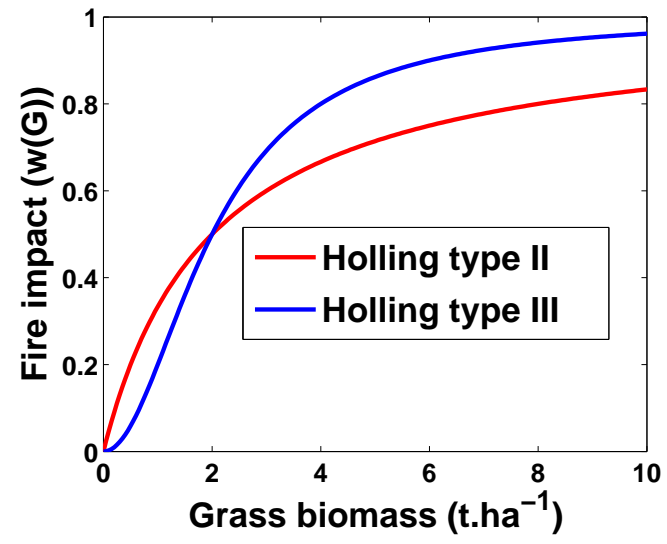

(b)

Figure 5: Graphical representation of the function shapes $w(G)$. The fire impact term in the ODEs is given by $\lambda_{f T} f \omega(G)$.

Table III: Functions involving $\omega(G)$.

\begin{tabular}{lcc}
\hline Functions & Models (ODE) & $\begin{array}{c}\text { Coexistence } \\
\text { equilibria }\end{array}$ \\
\hline$\omega(G)=0$ & Tilman (1994) [94] & $\begin{array}{l}\text { One savanna } \\
\text { monostability }\end{array}$ \\
\hline$\omega(G)=G$ & Accatino et al. (2010) [4] & 2 savannas \\
& Van Langevelde et al. (2003) [101] & bistability \\
\hline $\begin{array}{l}\text { Holling } \\
\text { type II }\end{array}$ & Tchuinté Tamen et al. (2014) [91] & $\begin{array}{l}2 \text { savannas } \\
\text { bistability }\end{array}$ \\
\hline \multirow{3}{*}{$\begin{array}{l}\text { Holling } \\
\text { type III }\end{array}$} & Tchuinté Tamen et al. (2014) [91] & $\begin{array}{l}3 \text { savannas } \\
\text { bistability }\end{array}$ \\
\cline { 2 - 3 } & Yatat et al. (2014) [112] & $\begin{array}{l}3 \text { savannas } \\
\text { bistability \& } \\
\text { tristability }\end{array}$ \\
\hline
\end{tabular}

[78], modelling savanna dynamics in fire-prone contexts actually requires introducing an "equation predicting the effect of grass biomass, via fire intensity, on tree biomass".

In fact, non-linearity in $\omega(G)$ may be justified on various, non-exclusive grounds, since what is important is to properly model, as a whole, the causal chain that leads from grass abundance and ignition regime to woody biomass suppression. As steps in this chain we may identify: (i) fire frequency to be seen as an external forcing upon the tree-grass system (think about a targeted fire regime in a managed area such as a ranch or a protected area); (ii) actual yearly fire probability (or frequency) of occurrence in any arbitrary small piece of land once (i) has been set; (iii) fire potential impact (intensity and flame height) on woody vegetation; (iv) fire actual impact that also depends on features intrinsic to woody vegetation (see below section IV-C).

Fire intensity which is strictly speaking a quantity of energy released (Bond and Keeley (2005) 


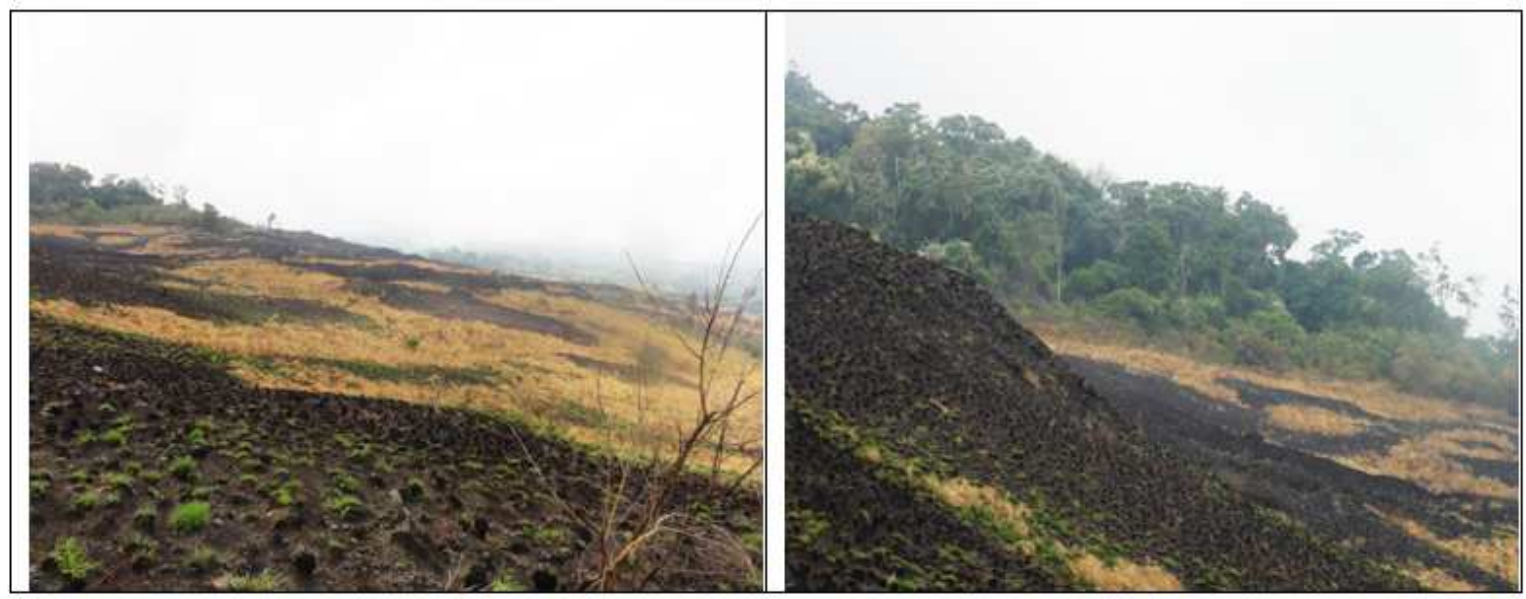

Figure 6: Example of spatial heterogeneity of fire propagation in an altitude mosaic of forests and low biomass grasslands in Cameroon. Here local community hunters tend to set fire every year at landscape scale (i.e. $f=1$ ) as to flush small game from spots of dense grass cover. But all the area does not burn every year because fire actually do not propagate everywhere (From P. Couteron, February 2017, Mount Cameroon National Park).

[18]) appears empirically as a fairly linear function of grass biomass. But impact on trees also depends on flame height which is reported as increasing exponentially with observed quantity of dry grass biomass (Scheiter and Higgins (2007) [77], Staver et al. (2011) [83], Synodinos et al. (2018) [86]), though one may suppose some levelling off for maximal grass biomass (and height) values. In earlier works (Yatat et al. (2014) [112], (2017) [110], (2018) [109], Tchuinté Tamen et al. (2014) [91], (2016) [89], (2017) [90]), we systematically assumed fire impact on woody vegetation as a non-linear, increasing bounded function of grass biomass (Yatat et al. (2014) [112], (2017) [110], (2018) [109], Tchuinté Tamen et al. (2014) [91], (2016) [89], (2017) [90], (2018) [88]), $w(G)$.

In our modelling, the $f$ parameter was kept as constant multiplier of $w(G)$, but we interpret it as a man-induced "targeted" fire frequency (as for instance in a fire management plan), which will not translate into actual frequency of fires of notable impact as long as grass biomass is not of sufficient quantity. With this interpretation, the actual fire regime may substantially differ from the targeted one, as frequently observed in the field. And, whatever $f$ values, any hypothetical piece of land will actually be fire-prone only if other forcing factors (climate, herbivory, etc.) allow for sufficient grass biomass. Most previous modelling papers including those from our group did not elaborate much regarding the successive steps involved in the grass-fire feedback. Distinction between (i) and (ii) may appear subtle and to our knowledge was never emphasized before. It directly results from space-implicit savanna modelling. Fire regime, which is nowadays overwhelmingly maninduced (Govender et al (2006) [44], Archibald (2009) [7]) is a forcing at landscape scale since people do not go and set fire in every piece of land. They instead count on fire propagation that depends on abundance and spatial evenness of dry grass. In presence of low and unevenly distributed grassy fuel, fire will barely propagate leaving a large share of the area unburnt. This makes the difference between steps (i) and (ii), as frequently observed in the field (see Diouf et al. (2012) [31]; Figure (6). The response of percent area burnt to grass abundance is likely to be sharply nonlinear, as suggested by the impressive results reported by McNaughton (1992) [61] at the scale of the entire Serengeti complex in Tanzania. In this remarkable study, local fire frequency dwindled over a decade 
following grass biomass suppression by soaring herbivore populations, while the ignition regime by people dwelling around the park likely remained more or less the same. In fact, since we are here dealing with mean-field models the $\omega(G)$ function is also due to embody the difficult spreading of fire in presence of fuel of overall low quantity keeping in mind natural spatial variability of grass biomass (Figure 6). Non-linearity of $\omega(G)$ seems therefore a necessary feature for adequately capturing the fire-mediated grass-tree feedback.

\section{Tree survival}

To be relevant, the most parsimonious models featuring just grass and tree state variables must overcome the limitation pointed out in sub-section IV-A for the precursor model of Accatino et al. (2010) [4]. All things being equal, any increase in fire frequency should never increase the woody component of vegetation. Fire, if any, is expected to be of no substantial consequence over the driest stretch of the rainfall gradient while for the moister part, it is widely observed that extending the average time between successive fires (decreasing frequency) favours the building up of woody vegetation. Accounting for that proved to be a challenge for minimal two-variable models that do not distinguish between fire sensitive and fire insensitive woody fractions. Non-linearity of the $\omega(G)$ function, though important proved not sufficient to overcome this problem. Tchuinté Tamen et al. (2017) [90] further introduced a second non-linear decreasing function, which directly expresses that high woody biomasses, corresponding to tall trees proportionately experience far less firerelated losses than low woody biomasses relating to seedlings, saplings and shrubs (see Figure 2). We hence proposed the following function to denote the fire-induced tree/shrub mortality:

$$
\vartheta(T)=\lambda_{f T}^{\min }+\left(\lambda_{f T}^{\max }-\lambda_{f T}^{\min }\right) e^{-p T},
$$

where $\lambda_{f T}^{\min }$ (in $\mathrm{yr}^{-1}$ ) is minimal loss of tree biomass due to fire in systems with a very large tree biomass, while $\lambda_{f T}^{\max }$ (in $\mathrm{yr}^{-1}$ ) is maximal loss of tree/shrub biomass due to fire in open vegetation (e.g. for an isolated small woody individual having its crown within the flame zone), $p$ (in $\mathrm{t}^{-1}$.ha) is proportional to the inverse of biomass suffering an intermediate level of mortality.

This general form was suggested by experimental observations showing dwindling rate of topkill with increasing tree height, since tall trees are likely to have their upper parts above the flame zone, even for high grass biomass (Trollope and Trollope (2010) [100]).

Notice that taking into account a nonlinear and decreasing function of tree biomass is a way to bypass introducing size classes as to keep the model minimal and retain mathematical tractability (see inspiring examples in Meron et al. (2004) [67], Lefever et al. (2009) [55]). The addition of the $\vartheta(T)$ function was indeed decisive in ensuring that a two-equation ODE system provides predictions that qualitatively agree with the general ecological knowledge about the role of fire return period. On this basis, Tchuinté Tamen et al. (2017) [90] designed a model that also implemented punctual fire events through impulsive differential equations. But predictions of the ODE model itself were already satisfactory.

\section{Relating to water resource}

Several savanna models have explicitly modelled soil water resources, via a dedicated equation as in system (3). But the soil moisture dynamics is very rapid compared to change in vegetation. Soil moisture variations linked to a given rainfall event are damped within a few days (Barbier et al. (2008) [10]), while vegetation growth proceeds over months for grasses and even years for woody plants. It therefore makes sense to consider vegetation dynamics in relation to a level of soil water resource that is approximately constant for a given level of total annual rainfall or, ideally, water deficit (rainfall minus evapotranspiration). Martinez-Garcia et al. (2014) [59] reached similar conclusions for a partial differential equation model of non-local plant-plant interactions for water. This justifies letting parameters in the vegetation dynamics equations directly depend on 
climatic parameters. This principle sustains the model expressed through the following system:

$$
\left\{\begin{aligned}
\frac{d G}{d t}= & r_{G}(W) G\left(1-\frac{G}{K_{G}(W)}\right)-\delta_{G} G \\
& -\eta_{T G} T G-\lambda_{f G} f G, \\
\frac{d T}{d t}= & r_{T}(W) T\left(1-\frac{T}{K_{T}(W)}\right)-\delta_{T} T \\
& -f \vartheta(T) \omega(G) T \\
G(0)= & G_{0}, T(0)=T_{0},
\end{aligned}\right.
$$

where,

- $G$ and $T$ are grass and tree biomasses respectively;

- $W$ is the mean annual precipitation (in millimeters per year, mm. $\mathrm{yr}^{-1}$ );

- $r_{G}(W)=\frac{\gamma_{G} W}{b_{G}+W}$ and $r_{T}(W)=\frac{\gamma_{T} W}{b_{T}+W}$ are annual productions of grass and tree biomasses respectively, where $\gamma_{G}$ and $\gamma_{T}$ (in $\mathrm{yr}^{-1}$ ) express maximal growths of grass and tree biomasses respectively, half saturations $b_{G}$ and $b_{T}$ (in mm.yr ${ }^{-1}$ ) determine how quickly growth increase with water availability;

- $K_{G}(W)=\frac{c_{G}}{1+d_{G} e^{-a_{G} W}}$, and $K_{T}(W)=$ $\frac{c_{T}}{1+d_{T} e^{-a_{T} W}}$ are carrying capacities of grass and tree respectively, where $c_{G}$ and $c_{T}$ (in t.ha ${ }^{-1}$ ) denote the maximum values of the grass and tree biomasses, $a_{G}$ and $a_{T}$ $\left(\mathrm{mm}^{-1} \mathrm{yr}\right)$ control the steepness of the curves of $K_{G}$ and $K_{T}$ respectively, and $d_{G}$ and $d_{T}$ control the location of their inflection points;

- $\delta_{G}$ and $\delta_{T}$ respectively express the rates of grass and tree biomasses loss by herbivores (grazing and/or browsing) or by human action;

- $\eta_{T G}$ denotes the asymmetric influence of trees on grass for light (shading) and resources (water, nutrients) which relate to competitive or facilitative influences;

- $\lambda_{f G}$ is the specific loss of grass biomass due to fire;
- $f=\frac{1}{\tau}$ is the fire frequency, where $\tau$ is the fire return period.

Submitting model (6) to bifurcation analysis provides Figure 7f(b) that is to be compared to Figure 77-(a) from Accatino et al. (2010) [4], which has been reobtained using Matcont (see Govaerts (2000) [42], Dhooge et al. (2003) [29], Govaerts et al. (2007) [43] and references therein). Both Figures 7 -(a) and 77-(b) are sensible regarding low fire frequencies for which increasing MAR leads to a sequence of physiognomies of increasing woody biomass (i.e., grassland, savanna, forest). But in Figure 7f(b), the improvement resulting from introducing $\omega(G)$ and $\vartheta(T)$ is apparent when increasing fire frequency $(f)$ at different levels of the rainfall gradient. For high MAR values, the expected physiognomy shifts from monostable forest to forest-grassland bistability. Indeed, in presence of high MAR, it is known that grasslands are due to be encroached by forest under fire prevention or even just because of decreasing fire frequencies (Jeffery et al. (2014) [51]). Our model accords with field observations in that a high fire frequency is indeed a necessary condition to perpetuate the grassland (or savannas of low woody biomass) physiognomies. Moreover, largescale observations of bimodality between high and very low woody cover situations (Hirota et al. (2011) [47], Favier et al. (2012) [36]) can be accounted for by the forest-grassland bistability, though the converse is not necessarily true. In fact bimodality may stem from either transient situations or topographical heterogeneity and does not automatically implies bistability. For low to intermediate MAR values, say $600-1000 \mathrm{~mm}$, fire is known to be less pervasive, though field observations or experiment results depict woody vegetation thickening in case of fire frequency decrease (Brookman-Amissah (1980) [25]). The model is able to render such thickening as a shift from the grassland to the savanna stability domain. The model also predicts forest-savanna or savanna-grassland bistability, and even tristability thereof for restricted domains in the MAR-fire frequency plane that were situated around 1000 
$\mathrm{mm}$ of MAR. This value is of course dependent on parameter values used for computations underlying figure 7f(b). Refined calibrations relating to a specific regional context may displace the thresholds. Notably, the parameter expressing the influence of woody biomass on grasses proved to be influential on the thresholds between vegetation states (Tchuinté Tamen et al. (2018) [88]).

\section{E. Impulsive time-periodic occurrences of fire events}

In previous models, the traditional timecontinuous fire forcing formalism is often used. However, it is questionable to model fire as a permanent forcing that continuously removes fractions of fire sensitive biomass all over the year. Indeed, several months and even years can pass between two successive fires, such that fire may be considered as an instantaneous perturbation of the savanna ecosystem (Yatat et al. (2017) [110], Tchuinté Tamen (2016) [89], (2017) [90]; see also Table IV, page 18). Several recent papers have proposed to model fires as stochastic events while keeping the continuous-time differential equation framework (Baudena et al. (2010) [11], Beckage et al. (2011) [13], Klimasara and Tyran-Kamińska (2018) [54], Synodinos et al. (2018) [86]) or using a time-discrete model (Higgins et al. (2000) [45], Accatino and De Michele (2013) [2], Accatino et al. (2016) [5]). However, a drawback of most of the aforementioned recent time-discrete stochastic models (Higgins et al. (2000) [45], Baudena et al. (2010) [11], Beckage et al. (2011) [13]) is that they barely lend themselves to analytical approaches.

Based on Table IV page 18, we further consider in our group (Yatat et al. (2017) [110], (2018) [109], Yatat and Dumont (2018) [111], Tchuinté Tamen (2016) [89], (2017) [90], (2018) [88]) impulsive time-periodic fire events which is an approximation that keeps the potential of analytical investigation as large as possible while modelling discrete fires. An impulsive differential equations system can be used to express fire through impul- sive periodic occurrences (e.g. system (7), below):

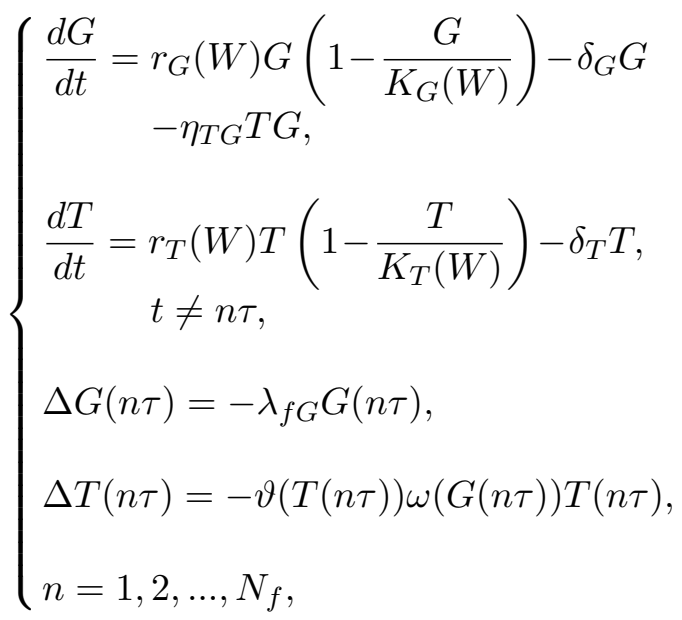

where,

- for $\pi \in\{G, T\}, \Delta \pi(n \tau)=\pi\left(n \tau^{+}\right)-\pi(n \tau)$ and $\pi\left(n \tau^{+}\right)=\lim _{\theta \rightarrow 0^{+}} \pi(n \tau+\theta)$;

- $\tau=\frac{1}{f}$ is the period between two consecutive fires;

- $N_{f}$ is a countable number of fire occurrences;

- $n \tau, n=1,2, \ldots, N_{f}$, are called moments of impulsive effects of fire, and satisfy $0 \leq \tau<$ $2 \tau<\ldots<N_{f} \tau$.

Properties of models (6) and (7) have been analysed in Tchuinté Tamen et al. (2018) [88]. Below we provide some numerical simulations as to illustrate the bifurcations between the stable domains delineated in Figure 7 $\mathrm{f} b$ as a consequence of increasing the fire frequency for two particular values of MAR, i.e. $\mathrm{W}=946 \mathrm{~mm} \cdot \mathrm{y}^{-1}$ and $\mathrm{W}=$ $1003 \mathrm{~mm} \cdot \mathrm{y}^{-1}$. For each of the two MAR values, we compare the consequences of increasing $f$ with the ODE (system (6)) and the IDE (system (7)) frameworks, by comparing Figure 8 against Figure 9 and Figure 10 against Figure 11 . For the lower MAR situation, ODE and IDE frameworks qualitatively agree and show the bifurcation from monostable savanna to monostable grassland through an intermediate bistable situation (Figure 8-b; Figure 9-b). For the higher MAR case, both frameworks also show the transition from monostable forest to forest-grassland bistability through tristability involving savanna. Qualitatively, the 


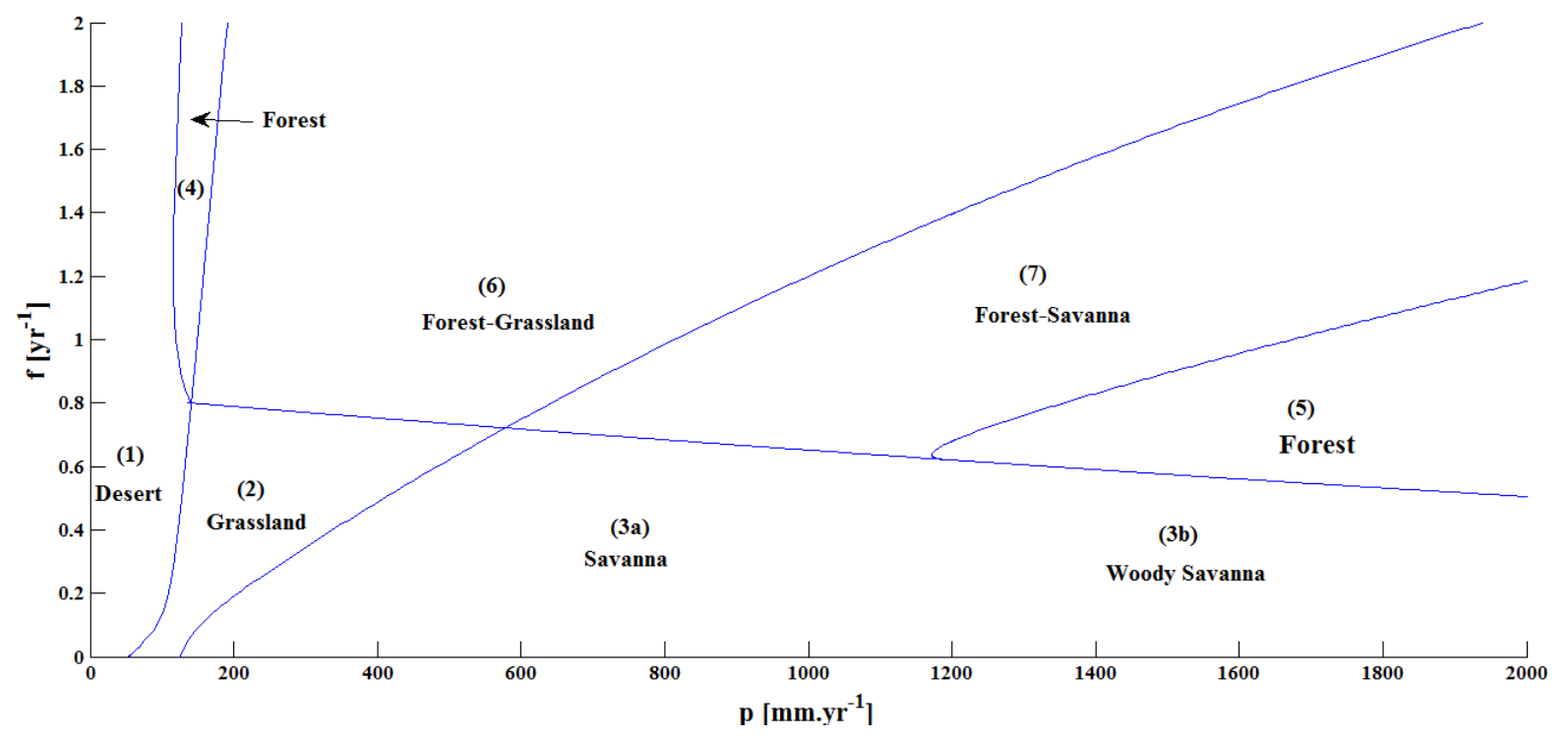

(a)

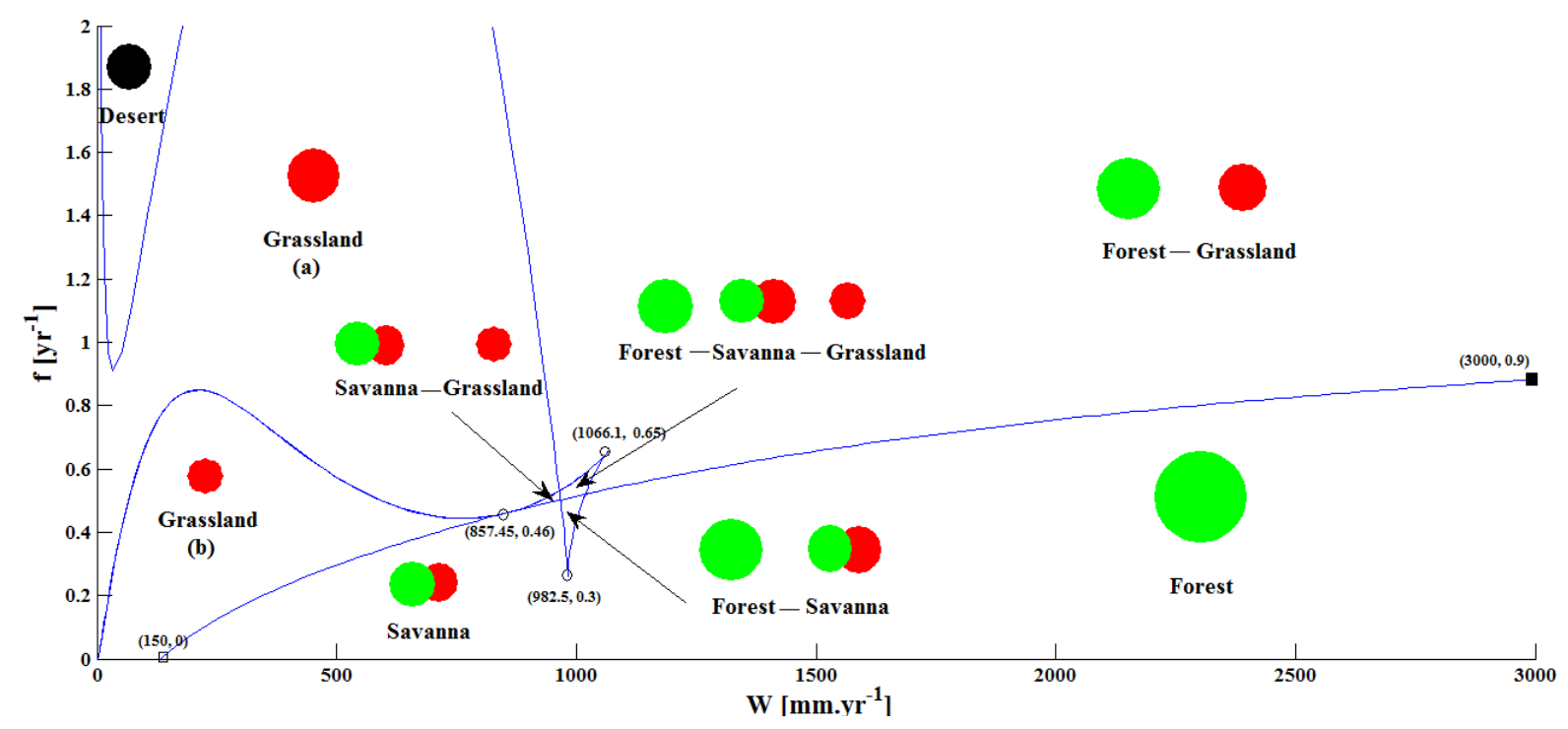

(b)

Figure 7: Bifurcation diagrams using Matcont. (a) Accatino et al. (2010) [4] model re-implementation. (b) Implementation of system 6). Single red, green and black symbols (rectangles in panel (a), dots in panel (b)) stand for grassland, forest and desert respectively. Twinned red and green symbols stand for savanna (coexistence state). Size of the symbols qualitatively denote grass and tree cover fractions in panel (a) and biomass levels in panel (b). Parameters used to compute Figure 7f(a) are from Accatino et al (2010) [4] (see also Table V in appendix). The parameter values used in 7f(b) are from Tchuinté Tamen et al. (2018) [88] (see also Table VI in appendix). (Color in the online version). 
I.V. Yatat Djeumen, A. Tchuinté Tamen, Y. Dumont, P. Couteron, A tribute to the use of minimalistic ...

Table IV: Average fire period ( $\tau$, in $y r)$ ranges of values found in literature with respect of the mean annual rainfall (MAR). Ranges of values of MAR are from Yatat et al. (2017) [110] and Tchuinté Tamen et al. (2016) [89]

\begin{tabular}{|c|c|c|}
\hline & \\
\hline & Ranges & References \\
\hline \multirow{2}{*}{$\begin{array}{c}\text { Low MAR: } \\
\text { MAR } \leq 650 \mathrm{~mm} \cdot \mathrm{yr}^{-1}\end{array}$} & $5-50$ & Frost and Robertson (1985) [40] \\
\hline & $4-8$ & Trollope (1984) [97] \\
\hline \multirow{2}{*}{$\begin{array}{c}\text { Intermediate MAR: } \\
650 \mathrm{~mm} \cdot \mathrm{yr}^{-1} \leq \mathrm{MAR} \leq 1100 \mathrm{~mm} \cdot \mathrm{yr}^{-1}\end{array}$} & $3-5$ & February et al. (2013) [38] \\
\hline & $5-7$ & Van Wilgen et al. (2004) [102] \\
\hline \multirow{4}{*}{$\begin{array}{c}\text { High MAR: } \\
\text { MAR } \geq 1100 \mathrm{~mm} \cdot \mathrm{yr}^{-1}\end{array}$} & $0.5-3$ & Jeffery et al. (2014) [51] \\
\hline & $0.5-2$ & $\begin{array}{l}\text { Bond and Keeley (2005) [18] } \\
\text { Accatino et al. (2010) [4 }\end{array}$ \\
\hline & $1-5$ & Abbadie et al. (2006) [1] \\
\hline & 1 & $\begin{array}{l}\text { Menaut and Cesar (1979) [63 } \\
\text { Gignoux et al. (2009) } 41]\end{array}$ \\
\hline
\end{tabular}

predictions of the two frameworks agree about the predicted sequence of vegetation physiognomies when increasing the fire frequency. However, the IDE model systematically predicted bifurcations for lower values of $f$ than for the ODE. This indicates that shifting to the conceptually more satisfactory IDE framework will introduce specificities in forthcoming stages concerning refined calibration and comparison with real-world observations.

\section{DISCUSSION AND PROSPECTS}

In the present paper we emphasize that ecologists did probably not yet exploit all the potential of simple ODE systems for modelling vegetation dynamics in the savanna biome to which most seasonal tropical ecosystems pertain. We showed that reasonable, non-trivial predictions can be obtained in reference to hypothetical situations directly relating to rainfall and fire frequency gradients. Application to specific contexts and locations would request refined calibration for the parameters of the generic minimalistic model. But it may also invite to better address specific processes deemed influential in a particular situation under study. This would mean complexifying the model to match a specific piece of reality. Though this is actually a natural and sensible trend in science, parsimony is an opposing principle that tells us to keep complexification under control. A meaningful, balanced modelling approach should restrict to what we strictly need to account for a well-defined array of empirical facts in a particular situation.

On the empirical side, the ongoing development of remote-sensing techniques and derived products is providing avenues to better depict the spatiotemporal variation of environmental factors, such as rainfall (e.g. via CHELSA, Karger et al. (2017) [52]), topography (via the SRTM, Farr et al. (2007) [35], published at increased spatial resolution by NASA in 2013) or fires (http://modis-fire.umd.edu; e.g. Archibald et al. (2009) [7], Diouf et al. (2012) [31]). This also applies to the monitoring of some vegetation variables, though disentangling effects on most remotely-sensed signals from grasses vs. trees in mixed savanna physiognomies is still challenging. Improving and diversifying sources of remote sensing information will obviously help sorting out relevant predictions from unrealistic ones and refine the benchmarking of models. But most of the parameters expressing vegetation dynamics will remain out of reach of remotelysensed assessment and will remain dependent on field information. An increased effort of field data 


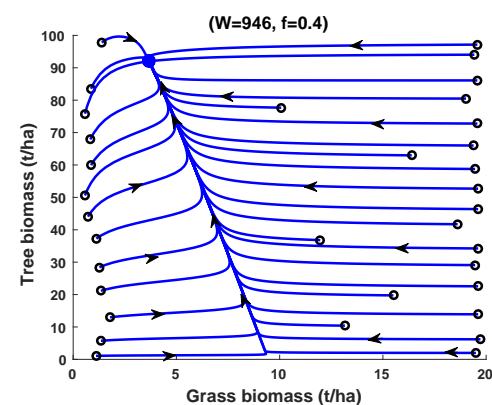

(a)

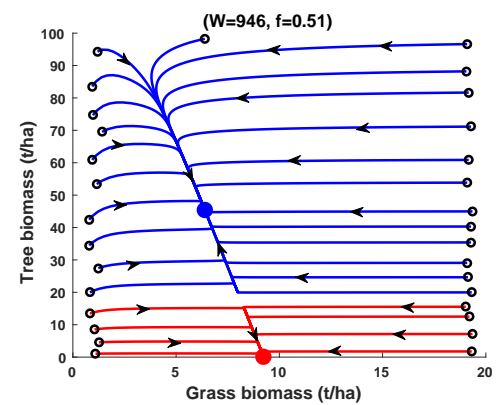

(b)

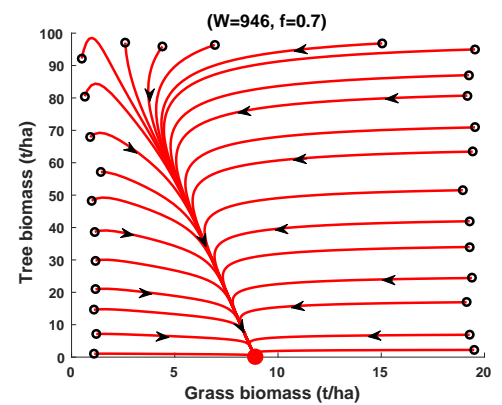

(c)

Figure 8: Illustration of a bifurcation due to $f$ with the ODE model of system 6 for a constant MAR value of W=946 mm.y ${ }^{-1}$. When the fire frequency $f$ increases, the system shifts from a savanna monostable (see panel (a)) to a grassland monostable (see panel (c)) passing through a bistability between savanna and grassland (see panel (b)).

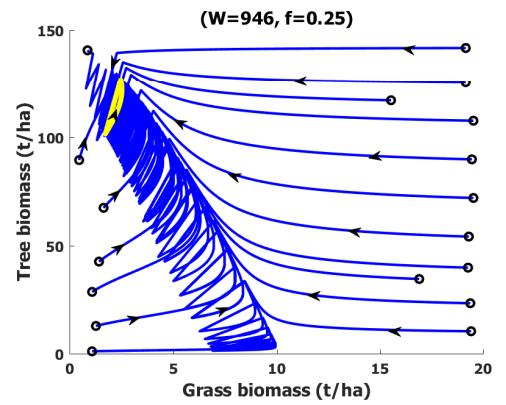

(a)

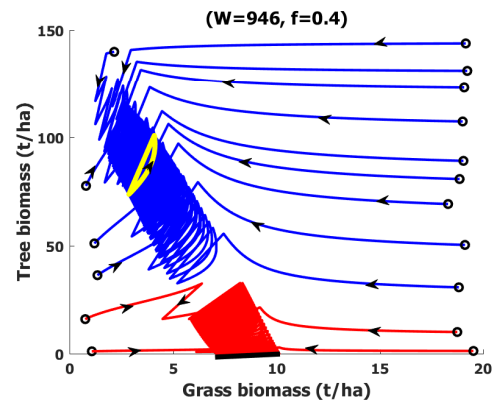

(b)

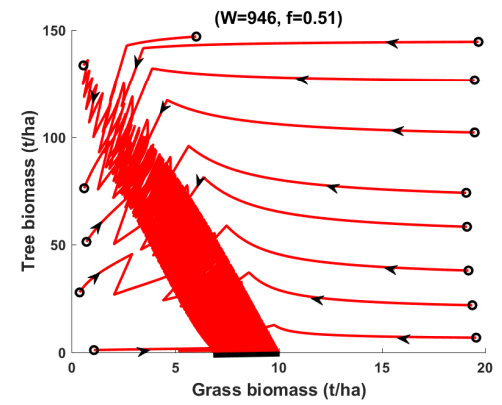

(c)

Figure 9: Illustration of a bifurcation due to fire frequency $f$ with the impulsive model 7 for a constant MAR value of W=946 mm.y ${ }^{-1}$ This figure is based on same parameters values as Figure 8 but with the impulsive IDE framework savanna-grassland bistability is already observable for $f=0.4$ (panel (a)) and give way to monostable grassland for $f=0.51$ (panel (b)). These values are to be compared to $f=0.25$ and $f=0.7$, respectively when using the ODE model (system 6 ).

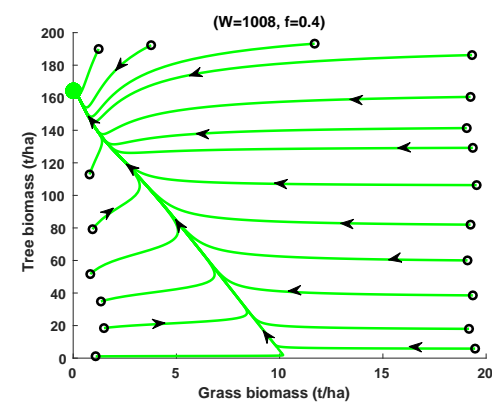

(a)

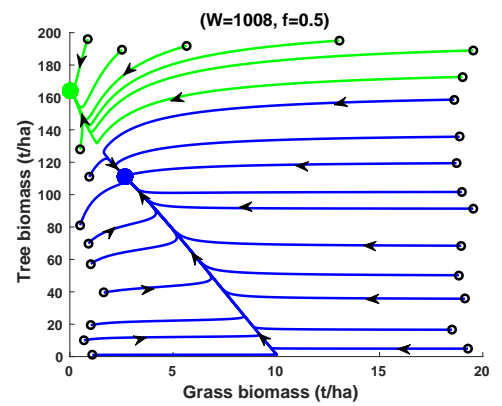

(b)

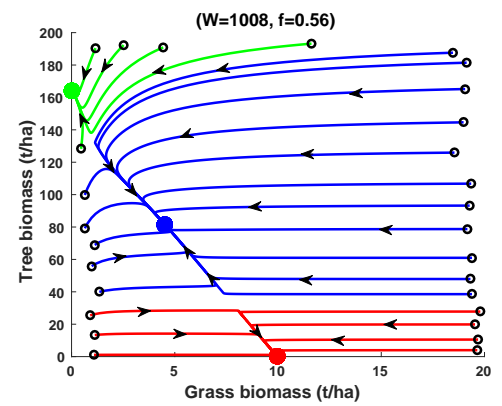

(c)

Figure 10: Numerical simulations with the ODE model 6 illustrating a bifurcation induced by increasing the fire frequency $(f)$ in presence of a constant MAR (W) value of $1008 \mathrm{mmy}^{-1}$. Vegetation shifts from monostable forest (left) to savanna-forest bistability (center) to grassland-savanna-forest tristability (right). 


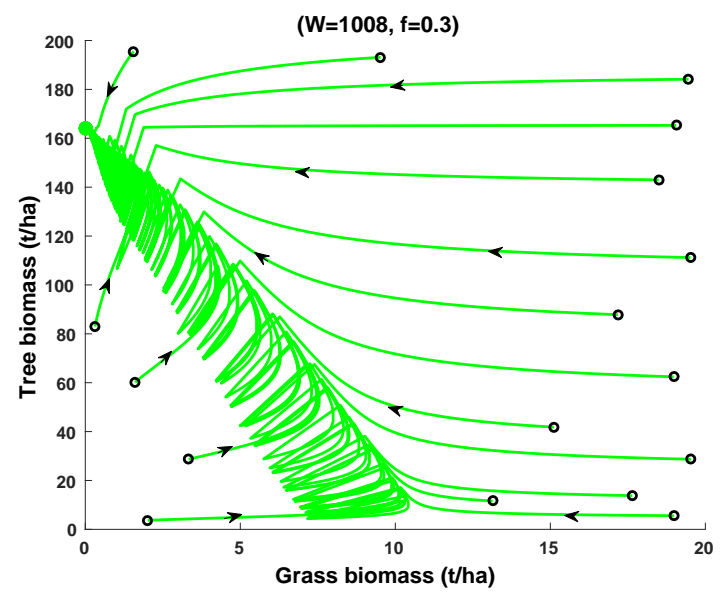

(a)

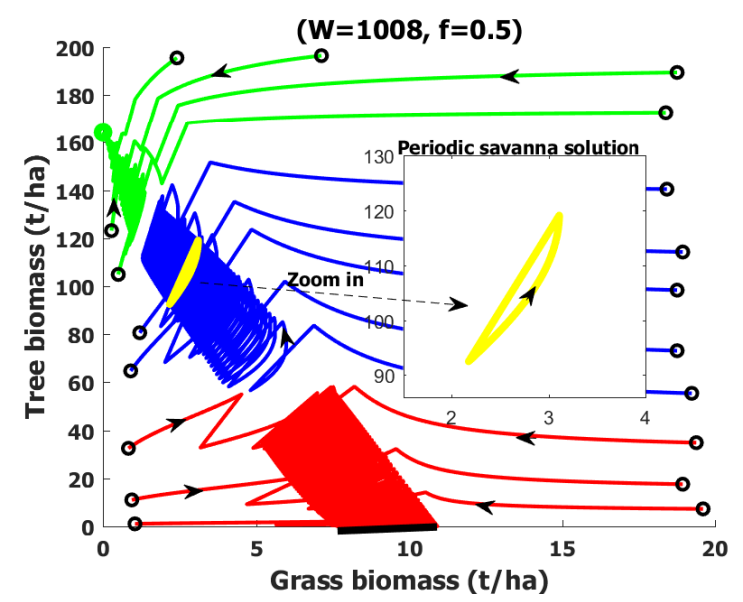

(c)

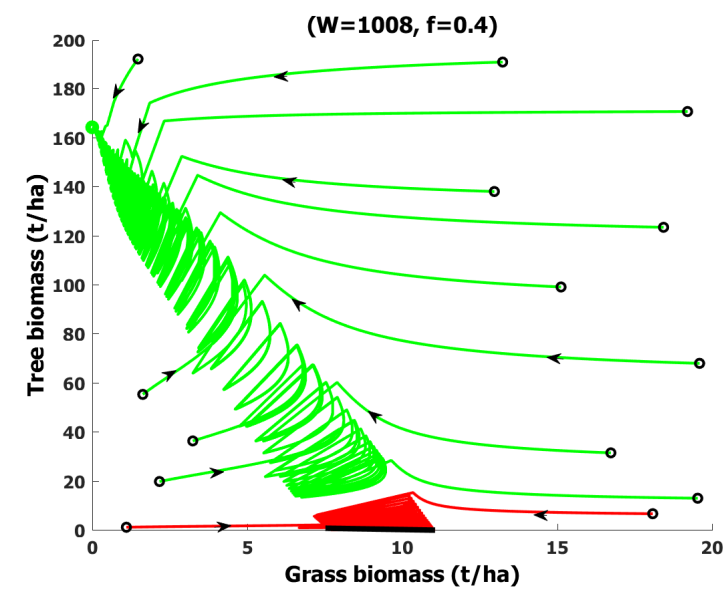

(b)

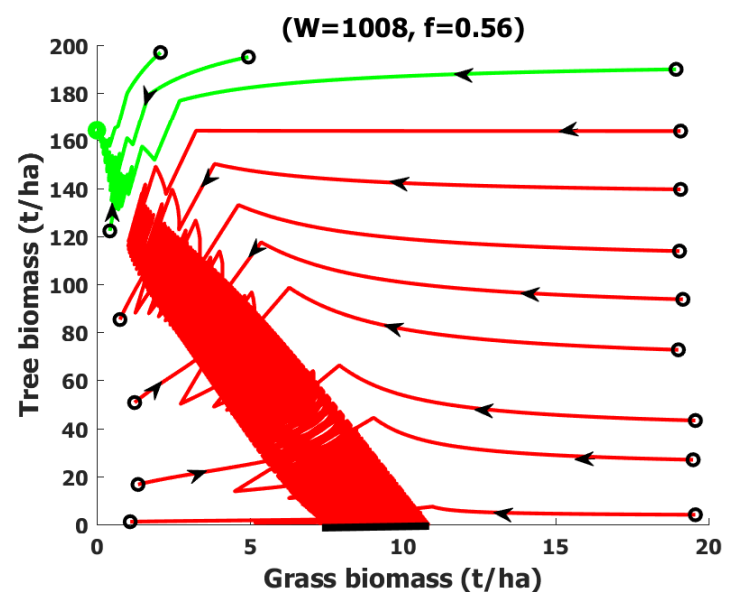

(d)

Figure 11: Numerical simulations with the IDE model 7 illustrating a bifurcation induced by increasing the fire frequency $(f)$ in presence of a constant MAR (W) value of $1008 \mathrm{~mm}^{-1}$. This figure is analogous to Figure 10 obtained with the ODE model. Note that with the ODE model, there is still tristability for $f=0.56$ while forest is still monostable for $f=0.4$.

collection is obviously desirable but insufficient means for research in most tropical countries is enduring reality. That strong data limitation is alas probably here to stay finally pleads for parsimony in modelling. It also underlines the importance for modelling to be sufficiently convincing and accessible to ecologists as to guide data acquisition and orient scarce resources towards assessing parameters proven as the most influential by sensibility analyses.
On the modelling side, within the class of models that distinguished size classes for the woody component of vegetation, some used more than two size classes through matrix population models (e.g. Accatino et al. (2013) [2], (2016) [5]). However, such models remain generally simulationbased and usually involve a fairly large number of parameters. Thus, it is not easy/possible to assess how model parameter variations may influence the model outcomes (Yatat et al. (2018) [109]). ODE 
and IDE models featuring two woody variables, in addition to grass, proved analytically tractable (Beckage et al. (2009) [14], Staver et al. (2011) [83], Yatat et al. (2014) [112], (2017) [110]) as long as other complexities were not introduced. For example, Yatat et al. (2014) [112] (resp. Yatat et al. (2017) [110]) studied a ODE-like (resp. IDE-like) tree-grass interactions model where in addition to grass they considered two classes of woody plants: fire-sensitive like seedlings and fire insensitive. But, based on recent publications of our group, we found that even with models that feature only one state variable for woody component, meaningful results are obtained and, to some extent, are qualitatively similar to those obtained with models that used two size-related variables for woody component (Tchuinté Tamen et al. (2014) [91], (2016) [89], (2017) [90], (2018) [88], Yatat et al. (2018) [109]).

The IDE framework is an obvious improvement that expresses a reasonable trade-off between increased realism and decreased analytical tractability. Within the framework of IDE, a further step in that direction could be considering patterns of fire occurrences featuring stochastic components instead of the deterministic periodic regime we used (Yatat et al. (2017) [110], (2018) [109], Tchuinté Tamen et al. (2016) [89], (2017) [90], (2018) [88]). But one may note here that periodicity of fire outbreaks is not that unrealistic in the context of subequatorial humid savannas for which fires can only occur at the end of dry seasons which are of short duration. Here the annual climatic cycle strongly defines the temporal window for fires while in less humid savannas fire is simultaneously less frequent and liable to occur all over extensive dry seasons (Diouf et al. (2012) [31]). We believe that while mathematical tractability or theoretical study of a model is not an absolute requirement or is not always possible, it remains nevertheless desirable at least for two reasons. First, it can appear as a kind of guarantee that numerical simulations displayed by the model are not the result of some numerical artifacts. In other words, the choice or the construction of a suitable algorithm to solve a given (complex) model strongly relies on its qualitative study or, when this study is not possible, on the analysis of some sub-models, that can be mathematically tractable. Nowadays, there are more and more works that point out some spurious behaviors that may appear when using some 'classical' schemes for model simulations (see for example Anguelov et al. (2012) [6]). Second, any theoretical analysis may provide useful informations about the role of some particular parameters in the dynamics of the system.

We have here focused on spatially-implicit models because we believe that such models have still important insights to provide and also because spatially-explicit models are far more demanding in terms of parametrization and more difficult to study theoretically. Substantial efforts to design and run spatial models of savannas have however been made during the last decade (Borgogno et al. (2009) [23]). Most of them relied on individual-based models such as cellular automata. At this step of the discussion, it seems meaningful to point out that there are some authors who pleaded for a mutualistic or complementary relationship between mathematical tractabilitybased and simulation-based formalisms (Omohundro (1984) [73], Wolfram (1985) [108], Weimar (1997) [106], Narbel (2006) [71], Dietrich et al. (2014) [30], Dumont et al. (2018) [34]) and we also agree with that. As an illustration, it may be more difficult to achieve a very deep theoretical analysis of a partial differential equations model when taking into account spatial heterogeneity while it seems more easy to handle it when using for example an individual-based model or cellular automaton formalism. Independently, partial differential equations (PDE) have also widely been used to account for the genesis of vegetation regular spatial patterns (bare soil vs. dense shrubby cover) in the particular context of arid savannas (Lefever and Lejeune (1997) [56], Klausmeier (1999) [53], Sherratt (2005) [81], Borgogno et al. (2009) [23], Lefever et al. (2009) [55], Meron (2011) [66], Lefever and Turner (2012) [57]). In 
this line, there was a recent attempt by Yatat et al. (2018) [109] to account for the dynamics of forestsavanna boundaries by introducing local diffusion operators for herbaceous and woody biomasses in a parsimonious space-implicit model, with timecontinuous fire events forcing, closely related to the one of Tchuinté Tamen et al. (2017) [90]. The analysis of this model shows that there exists monostable or bistable travelling solutions, related to the boundary movements in the forestgrassland mosaic. And the authors showed that depending on fire-return time as well as difference in diffusion coefficients of woody and herbaceous vegetation, fire events are able to greatly slow down or even stop the progression of forest in the humid part of the savanna biome. This kind of results, obtained from theoretical analysis, are of great interest for practical needs or management policies. However, as an improvement of Yatat et al. (2018) [109], there are also some ongoing works that aim to deal with existence of travelling waves for system of Impulsive Partial Differential Equations (IPDE) that model savanna dynamics (e.g. Yatat and Dumont (2018) [111]). This type of modelling is of great interest considering that the forest-savanna ecotone is the most widespread in the tropics and that forests have been encroaching during the last decades in many humid savannas of West and Central Africa, and to a lesser extent in other regions of the world (Oliveras and Malhi (2016) [72]). On the other hand, forest encroachment, which is of great consequence for the global carbon balance of terrestrial ecosystems proved heterogeneous in space and time (Oliveras and Malhi (2016) [72]). Hence, modelling should help better understand the hierarchy of processes and forces accounting for such heterogeneity. This makes spatially-explicit modelling desirable. But, interpretation and calibration of local, diffusion operators as used in Yatat et al. (2018) [109] cannot rely on much empirical knowledge in plant ecology. And one may note that this also applies to colonization rates between adjacent cells that are central to cellular automata models. In the case of PDEs, modelling non-local plant-plant interaction processes (e.g. through interaction kernels) is mathematically more challenging, though attempts in Martinez-Garcia et al. (2014) [59] and in Lefever et al. (2009) [55] or Lefever and Turner (2012) [57] nevertheless provide sources of inspiration.

A recent line of criticism questions the relevance of reasoning in reference to equilibrium states. There is indeed no compelling evidence that physiognomies presently observable correspond or even are close to predictable equilibria determined by current environmental conditions. In fact, parameters reflecting environmental variables, notably climate are due to fluctuate or even change through time. And vegetation, especially its woody component may be unable to keep pace with such variations and rather track them with delay thereby remaining distant from any equilibrium state. Long-lasting consequences of past climate periods probably still mark present vegetation. For instance, in Central Africa, concomitant to, drier period occurred some centuries ago (Europe's "Little Ice Age", 500-200 years BP), which probably provoked forest cover recession and fragmentation (Oslisly et al. (2013) [74]). The trend of widespread forest boundaries displacement within savannas, as observed during the last decades may be a delayed recovery after this past drier period that is progressing at slow and unequal pace owing to the counteracting influence of fires. Increased $\mathrm{CO}_{2}$ availability that favours $\mathrm{C} 3$ woody plants against $\mathrm{C} 4$ savanna grasses (Bond and Midgley (2000) [19]) may also reinforce this trend.

\section{CONCLUSION}

Minimal savanna models using ODE systems have been criticized from different standpoints. The first one was the poor realism of the overall picture made by the predicted stable equilibria. The present paper shows that some unrealistic predictions are not a direct drawback of the ODE framework, but rather derive from inadequate modelling of the crucial fire-mediated negative feedback of grassy biomass onto woody vegetation. Using nonlinear functions such as $\omega(G)$ and $\vartheta(T)$ (as in equations 5 ) is not only justified by the 
nature of the mechanisms at play, but also proved sufficient to get a meaningful "big picture" of vegetation physiognomies predicted as stable for varying mean annual rainfall and fire frequency (as in Figure 7f(b)). Another argument against ODE models is that they predict too contrasted stable states meaning that shifts between them would appear as more catastrophic than actually observed. But some strong contrasts such as landscape mosaics of forest and grassland are indeed observable in the field (see Figure 1). Moreover equilibria that have attraction domains "adjacent" in Figure 7 do not systematically show contrasted biomass values. Transitions may actually be progressive in terms of state variables. Indeed, at low fire frequency, the transition from savanna to forest along the MAR gradient corresponds to a continuous increase of tree biomass with concomitant decrease of grass biomass. The same applies to the transition from savanna to grassland via increased fire frequency (see Figures 8 and 9). Here, the shape of the nonlinear functions embodying the grass-fire feedback matters as shown in previous works (Yatat et al. (2014) [112], Tchuinté Tamen et al. (2014) [91]). Strongly nonlinear shapes (e.g. Holling functions of higher order see Table III) allow for multiple coexistence equilibria (i.e. multiple savanna physiognomies) of different woody biomass values, which may be seen as "stepping stones" between grassland and forest. Thus, the ODE framework does not automatically imply abrupt changes between equilibria of very contrasted biomass values.

On the other hand, it is undisputable that modelling fire as an external forcing continuously suppressing small amount of biomass through time is not satisfactory. Models based on punctual fires impacting large shares of biomasses are more relevant. This is implemented in time-discrete stochastic models which are however of limited analytical tractability. Impulsive differential equation systems are a good compromise since they permit to model time-discrete fire impact while keeping ODE for modelling vegetation growth. As such, they remain analytically tractable to a large extent while being more realistic.
In this paper, we show that minimal savanna models are able to provide a wide array of meaningful and relevant predictions of savanna dynamics while retaining sufficient mathematical tractability and restricting themselves to a minimal set of parameters assessable from the overall literature. Moreover, simplicity is overarching whatever the level of tractability. With a simple model, simulations can claim a thorough exploring of all parameters space. Conversely, it is difficult to be sure that sufficient exploration of model behaviors has been carried out for overcomplicated models which tend to flourish in ecology. Moreover, because there is naturally substantial uncertainty for many parameter values, it is difficult to conclude whether results are due to the ranges taken for parameters or to the structure of the model itself. Therefore, using complex models, it becomes even more illusory to test hypotheses, while this is one of the fundamental roles of modelling.

\section{ACKNOWLEDGEMENTS}

A. Tchuinté Tamen and I.V. Yatat Djeumen are grateful to the French National Institute for Research for Sustainable Development (IRD), the French Agricultural Research Centre for International Development (CIRAD), the French Institute for Research in Computer Science and Automation (INRIA, EPI MASAIE), the Department of Cooperation and Cultural Action (SCAC) of the French Embassy in Yaoundé, the International Center for Pure and Applied Mathematics (CIMPA), the International Laboratory for Computer Sciences and Applied Mathematics (LIRIMA), the annual international conference on Mathematical Methods and Models in Biosciences (BIOMATH 2016 \& 2017), for their financial supports during the preparation of their Ph.D theses. I.V. Yatat Djeumen also acknowledges the support of the SARChI Chair in Mathematical Models and Methods in Bioengineering and Biosciences (University of Pretoria, South Africa).

\section{REFERENCES}

[1] L. Abbadie, J. Gignoux, X. Le Roux, and M. Lepage. Lamto: structure, functioning, and dynamics of a Savanna Ecosystem. Springer, 2006. 
[2] F. Accatino and C. De Michele. Humid savanna-forest dynamics: A matrix model with vegetation-fire interactions and seasonality. Ecol. Modell., 265(0):170-179, 2013. URL: http://dx.doi.org/10.1016/j.ecolmodel. 2013.05.022

[3] F. Accatino and C. De Michele. Interpreting woody cover data in tropical and subtropical areas: Comparison between the equilibrium and the non-equilibrium assumption. Eco. Comp., 25:60-67, 2016. URL: http://dx.doi.org/10.1016/j.ecocom.2015.12.004.

[4] F. Accatino, C. De Michele, R. Vezzoli, D. Donzelli, and R. Scholes. Tree-grass co-existence in savanna: interactions of rain and fire. J. Theor. Biol, 267:235242, 2010. URL: http://dx.doi.org/10.1016/j.jtbi.2010. 08.012

[5] F. Accatino, K. Wiegand, D. Ward, and C. De Michele. Trees, grass, and fire in humid savannas: The importance of life history traits and spatial processes. Ecol. Modell., 320:135-144, 2016. URL: http://dx.doi.org/ 10.1016/j.ecolmodel.2015.09.014

[6] R. Anguelov, Y. Dumont, and J.M. Lubuma. On nonstandard finite difference schemes in biosciences. AIP Conf. Proc., 1487:212-223, 2012.

[7] S. Archibald, D.P. Roy, B. Van Wilgen, and R.J. Scholes. What limits fire? an examination of drivers of burnt area in southern africa. Global Change Biol., 15:613-630, 2009. URL: http://dx.doi.org/10.1111/j. 1365-2486.2008.01754.x

[8] P. Augier, C. Lett, and J.C. Poggiale. Modelisation mathematique en ecologie. Cours et exercices corrigés. Dunod, 2010.

[9] I. Backéus. Distribution and vegetation dynamics of humid savannas in Africa and Asia. J. Veg. Sci., 3(3):345-356, 1992. URL: https://doi.org/10.2307/ 3235759

[10] N. Barbier, P. Couteron, R. Lefever, V. Deblauwe, and O. Lejeune. Spatial decoupling of facilitation and competition at the origin of gapped vegetation patterns. Ecology, 89:1521-1531, 2008. URL: https: //www.ncbi.nlm.nih.gov/pubmed/18589517

[11] M. Baudena, F. D'Andrea, and A. Provenzale. An idealized model for tree-grass coexistence in savannas: the role of life stage structure and fire disturbances. $J$. Ecol., 98:74-80, 2010. URL: http://dx.doi.org/10.1111/ j.1365-2745.2009.01588.x

[12] M. Baudena, S.C. Dekker, P.M. Van Bodegom, B. Cuesta, S.I. Higgins, V. Lehsten, C.H. Reick, M. Rietkerk, S. Scheiter, Z. Yin, M.A. Zavala, and V. Brovkin. Forest, savannas and grasslands: bridging the knowledge gap between ecology and dynamic global vegetation models. Biogeosciences Discuss., 11:9471-9510, 2014. URL: http://dx.doi.org/10.5194/ bgd-11-9471-2014

[13] B. Beckage, L.J. Gross, and W.J. Platt. Grass feedbacks on fire stabilize savannas. Ecol. Modell., 222:2227-2233, 2011. URL: http://dx.doi.org/10.1016/ j.ecolmodel.2011.01.015
[14] B. Beckage, W. Platt, and L. Gross. Vegetation, fire and feedbacks: a disturbance-mediated model of savannas. Am. Nat., 174(6):805-818, 2009. URL: http://dx.doi. org/0.1086/648458

[15] A.J. Belsky. Influuences of trees on savanna productivity: tests of shade, nutrients and tree-grass competition. Ecology, 75:922-932, 1994. URL: https://www.jstor. org/stable/1939416

[16] A.J. Belsky, R.G. Amundson, J.M. Duxbury, S.J. Rika, A.R. Ali, and S.M. Mwonga. The effects of trees on their physical, chemical, and biological environment in a semi-arid savanna in Kenya. J. Appl. Ecol., 26:1005-1024, 1989. URL: https://www.jstor. org/stable/2403708

[17] W.J. Bond. What limits trees in C4 grasslands and savannas ? Annu. Rev. Ecol. Evol. Syst., 39:641-659, 2008. URL: http://dx.doi.org/10.1146/annurev.ecolsys. 39.110707.173411

[18] W.J. Bond and J.E. Keeley. Fire as a global "herbivore":the ecology and evolution of flammable ecosystems. Trends in Ecoloy and Evolution, 20(7):387-394, 2005. URL: http://dx.doi.org/10.1016/j.tree.2005.04. 025

[19] W.J. Bond and G.F. Midgley. A proposed CO2controlled mechanism of woody plant invasion in grasslands and savannas. Global Change Biol., 6:865869, 2000. URL: https://doi.org/10.1046/j.1365-2486. 2000.00365.x

[20] W.J. Bond, G.F. Midgley, and F.I. Woodward. What controls south african vegetation-climate or fire? $S$. Afr. J. Bot., 69:79-91, 2003. URL: https://doi.org/10. 1016/S0254-6299(15)30362-8

[21] W.J. Bond and C. J. Parr. Beyond the forest edge: Ecology, diversity and conservation of the grassy biomes. Biol. Conserv., 143:2395-2404, 2010. URL: http: //dx.doi.org/10.1016/j.biocon.2009.12.012

[22] W.J. Bond, F.I. Woodward, and G.F. Midgley. The global distribution of ecosystems in a world without fire. New Phytol., 165:525-538, 2005. URL: http: //dx.doi.org/10.1111/j.1469-8137.2004.01252.x

[23] F. Borgogno, P. D’odorico, F. Laio, and L. Ridolfi. Mathematical models of vegetation pattern formation in ecohydrology. Rev. Geophys., 47, RG1005, 2009. URL: https://doi.org/10.1029/2007RG000256

[24] A. Bouvet, S. Mermoz, Thuy Le Toan, L. Villard, R. Mathieu, L. Naidoo, and G.P. Asner. An aboveground biomass map of african savannahs and woodlands at $25 \mathrm{~m}$ resolution derived from alos palsar. Remote Sensing of Environment, 206:156 - 173, 2018. URL: https://doi.org/10.1016/j.rse.2017.12.030

[25] J. Brookman-Amissah, J.B. Hall, Swaine. M.D., and J.Y. Attakorah. A re-assessment of a fire protection experiment in north-eastern Ghana savanna. Journal of Applied Ecology, 17(1):85-99, 1980. URL: http: //www.jstor.org/stable/2402965

[26] G. Bucini and N. P. Hanan. A continental-scale analysis of tree cover in african savannas. Global Ecol. 
Biogeogr., 16:593-605, 2007. URL: https://doi.org/10. 1111/j.1466-8238.2007.00325.x.

[27] A. Cuni-Sanchez, L. J. T. White, K. Calders, K. J. Jeffery, K. Abernethy, A. Burt, M. Disney, M. Gilpin, J. L. Gomez-Dans, and S. L. Lewis. African savannaforest boundary dynamics: A 20-year study. PLoS One, 11(6):e0156934, 2016. URL: https://doi.org/10.1371/ journal.pone.0156934

[28] C. De Michele, F. Accatino, R. Vezzoli, and R.J. Scholes. Savanna domain in the herbivores-fire parameter space exploiting a tree-grass-soil water dynamic model. J. Theor. Biol., 289(0):74-82, 2011. URL: http://dx.doi.org/10.1016/j.jtbi.2011.08.014

[29] A. Dhooge, W. Govaerts, and Yu. A. Kuznetsov. MATCONT: A MATLAB package for numerical bifurcation analysis of ODEs. ACM TOMS, 29(2):141-164, 2003. URL: http://dx.doi.org/10.1145/779359.779362

[30] F. Dietrich, G. Koster, M. Seitz, and I. von Sivers. Bridging the gap: From cellular automata to differential equation models for pedestrian dynamics. Journal of Computational Science, 5(5):841 - 846, 2014. URL: https://doi.org/10.1016/j.jocs.2014.06.005

[31] A. Diouf, N. Barbier, A.M. Lykke, P. Couteron, V. Deblauwe, A. Mahamane, M. Saadou, and J. Bogaert. Relationships between fire history, edaphic factor and woody vegetation structure and composition in a semiarid savanna landscape (niger, west africa). Appl. Veg. Sci., 15:488-500, 2012. URL: https://doi.org/10.1111/ j.1654-109X.2012.01187.x.

[32] P. D'odorico, F. Laio, and L. Ridolfi. A probabilistic analysis of fire-induced tree-grass coexistence in savannas. Am. Nat., 167(3):E79-E87, 2006. URL: http://dx.doi.org/doi:10.1086/500617.

[33] J. Dohn, F. Dembélé, M. Karembé, Aristides Moustakas, Kosiwa A. Amévor, and Niall P. Hanan. Tree effects on grass growth in savannas: competition, facilitation and the stress-gradient hypothesis. Journal of Ecology, 101(1):202-209, 2012. URL: http://dx.doi. org/10.1111/1365-2745.12010.

[34] Y. Dumont, J.-C. Soulie, and F. Michel. Modeling oil palm pollinator dynamics using deterministic and agent-based approaches. applications on fruit set estimates. some preliminary results. Mathematical Methods in the Applied Sciences, 0(0). URL: https: //doi.org/10.1002/mma.4858

[35] T.G. Farr, P.A. Rosen, E. Caro, R. Crippen, R. Duren, S. Hensley, M. Kobrick, M. Paller, E. Rodriguez, L. Roth, D. Seal, S. Shaffer, J. Shimada, J. Umland, M. Werner, M. Oskin, D. Burbank, and D. Alsdorf. The shuttle radar topography mission. Reviews of Geophysics, 45:RG2004, 2007. URL: http://dx.doi.org/ 10.1029/2005RG000183

[36] C. Favier, J. Aleman, L. Bremond, M. A. Dubois, V. Freycon, and J. M. Yangakola. Abrupt shifts in african savanna tree cover along a climatic gradient. Global Ecol. Biogeogr., 21:787-797, 2012. URL: http://dx.doi.org/10.1111/j.1466-8238.2011.00725.x
[37] C. Favier, J. Chave, A. Fabing, D. Schwartz, and M.A. Dubois. Modelling forest-savanna mosaic dynamics in man-influenced environments: effects of fire, climate and soil heterogeneity. Ecol. Modell., 171:85-102, 2004. URL: http://dx.doi.org/10.1016/j. ecolmodel.2003.07.003

[38] E.C. February, S.I. Higgins, W.J. Bond, and L. Swemmer. Influence of competition and rainfall manipulation on the growth responses of savanna trees and grasses. Ecology, 94:1155-1164, 2013. URL: https://doi.org/ 10.1890/12-0540.1.

[39] P. Frost, E. Medina, J.C. Menaut, O. Solbrig, and B. Walker. Responses of savannas to stress and disturbance. Biology International, S10:1-82, 1986. URL: http://iubs.org/pdf/publi/BISI/SPECIAL\% 20ISSUE\%2010a.pdf.

[40] P.G.H. Frost and F. Robertson. The ecological effects of fire in savannas. in b.h. Walker, editor, determinants of tropical savannas. International Council of Scientific Unions Press, Miami, FL, 3:93-140, 1985.

[41] J. Gignoux, G. Lahoreau, R. Julliard, and S. Barot. Establishment and early persistence of tree seedlings in an annually burned savanna. Journal of Ecology, 97:484-495, 2009. URL: https://doi.org/10.1111/j. 1365-2745.2009.01493.x

[42] W. Govaerts. Numerical bifurcation analysis for ODEs. J. Comput. Appl. Math., 125(1):57-68, 2000. URL: https://doi.org/10.1016/S0377-0427(00)00458-1.

[43] W. Govaerts, R.K. Ghaziani, Yu. A. Kuznetsov, and H.G.E. Meijer. Numerical methods for two-parameter local bifurcation analysis of maps. SIAM J. Sci. Comput., 29(6):2644-2667, 2007. URL: https://doi. org/10.1137/060653858

[44] N. Govender, W.S.W. Trollope, and B.W. Van Wilgen. The effect of fire season, fire frequency, rainfall and management on fire intensity in savanna vegetation in south africa. J. Appl. Ecol., 43(4):748-758, 2006. URL: http://dx.doi.org/10.1111/j.1365-2664. 2006.01184.x

[45] S. Higgins, W.J. Bond, and W. Trollope. Fire, resprouting and variability: a recipe for grass-tree coexistence in savanna. Journal of Ecology, 88:213-229, 2000. URL: http://dx.doi.org/10.1046/j.1365-2745. 2000.00435.x

[46] S.I. Higgins, S. Scheiter, and M. Sankaran. The stability of african savannas: insights from the indirect estimation of the parameters of dynamic model. Ecology, 91:1682-1692, 2010. URL: http://dx.doi.org/ 10.1890/08-1368.1

[47] M. Hirota, M. Holmgren, E. H. Van Nes, and M. Scheffer. Global resilience of tropical forest and savanna to critical transitions. Science, 334(6053):232-235, 2011. URL: http://dx.doi.org/10.1126/science.1210657

[48] W.A. Hoffmann, E.L. Geiger, S.G. Gotsch, D.R. Rossatto, L.C.R. Silva, O.L. Lau, M. Haridasan, and A.C. Franco. Ecological thresholds at the savannaforest boundary: how plant traits, resources and fire 
govern the distribution of tropical biomes. Ecology letters, 15(7):759-768, 2012. URL: https://doi.org/10. 1111/j.1461-0248.2012.01789.x

[49] R.M. Holdo, R.D. Holt, and J.M. Fryxell. Grazers, browsers, and fire influence the extent and spatial pattern of tree cover in the Serengeti. Ecol. Appl., 19(1):95-109, 2009. URL: https://www.ncbi.nlm.nih. gov/pubmed/19323175

[50] C.S. Holling. The components of predation as revealed by a study of small mammal predation on the european pine sawfly. Canadian Entomologist, 91:293-320, 1959. URL: https://doi.org/10.4039/Ent91293-5

[51] K.J. Jeffery, L. Korte, F. Palla, G. Walters, L.J.T. White, and K.A. Abernethy. Fire management in a changing landscape: a case study from lope national park, gabon. Parks, 20:39-52, 2014. URL: http: //hdl.handle.net/1893/21032.

[52] D.N. Karger, O. Conrad, J. Bohner, T. Kawohl, K. Kreft, R.W. Soria-Auza, N.E. Zimmermann, H.P. Linder, and M. Kessler. Climatologies at high resolution for the earth's land surface areas. Scientific Data, 4, 2017. URL: https://doi.org/10.1038/sdata.2017.122

[53] A. Klausmeier. Regular and irregular patterns in semiarid vegetation. Science, 284:1826-1828, 1999. URL: https://www.ncbi.nlm.nih.gov/pubmed/10364553

[54] P. Klimasara and M. Tyran-Kamińska. A model for random fire induced tree-grass coexistence in savannas. Arxiv, pages 1-8, 2018. URL: https://arxiv.org/abs/ 1806.03533

[55] R. Lefever, N. Barbier, P. Couteron, and O. Lejeune. Deeply gapped vegetation patterns: Oncrown/root allometry, criticality and desertification. J. Theo. Ecol., 261:194-209, 2009. URL: http://dx.doi.org/10.1016/j. jtbi.2009.07.030.

[56] R. Lefever and O. Lejeune. On the origin of tiger bush. Bul. Math. Biol., 59:263-294, 1997. URL: https: //doi.org/10.1007/BF02462004

[57] R. Lefever and J.W. Turner. A quantitative theory of vegetation patterns based on plant structure and the non-local F-KPP equation. C. R. Mecanique, 340:818-828, 2012. URL: http://dx.doi.org/10.1016/ j.crme.2012.10.030

[58] C. Lehmann, S. Archibald, W.A. Hoffmann, and W.J. Bond. Deciphering the distribution of the savanna biome. New Phytol., 191:197-209, 2011. URL: http: //dx.doi.org/10.1111/j.1469-8137.2011.03689.x

[59] R. Martinez-Garcia, J.M. Calabrese, E. HernandezGarcia, and C. Lopez. Minimal mechanisms for vegetation patterns in semiarid regions. Phil. Trans. R. Soc. A, 372, 2014. URL: http://dx.doi.org/10.1098/ rsta.2014.0068

[60] P. Mayaux, E. Bartholomé, S. Fritz, and A. Belward. A new land-cover map of africa for the year 2000. $J$. Biogeogr., 31(6):861-877, 2004. URL: http://dx.doi. org/10.1111/j.1365-2699.2004.01073.x

[61] S.J. McNaughton. The propagation of disturbance in savannas through food webs. J. Veg. Sci., 3(3):301314, 1992. URL: https://www.jstor.org/stable/3235755

[62] S.J. McNaughton and N. J. Georgiadis. Ecology of african grazing and browsing mammals. Annual review of ecology and systematics, 17(1):39-66, 1986. URL: http://dx.doi.org/10.1146/annurev.es.17.110186. 000351

[63] J.C. Menaut and J. Cesar. Structure and primary productivity of lamto savannas, ivory coast. Ecology, 60:1197-1210, 1979.

[64] S. Mermoz, T. Le Toan, L. Villard, M. Réjou-Méchan, and J. Seifert-Granzin. Biomass assessment in the cameroon savanna using alos palsar data. Remote Sening of Environment, 2014. URL: http://dx.doi.org/ 10.1016/j.rse.2014.01.029

[65] S. Mermoz, M. Réjou-Méchan, L. Villard, T. Le Toan, V. Rossi, and S. Gourlet-Fleury. Decrease of Lband SAR backscatter with biomass of dense forests. Remote Sening of Environment, 159:307-317, 2015. URL: https://doi.org/10.1016/j.rse.2014.12.019

[66] E. Meron. Pattern-formation approach to modelling spatially extended ecosystems. Ecol. Model., 2011. URL: https://doi.org/10.1016/j.ecolmodel.2011.05.035

[67] E. Meron, E. Gilad, J. Von Hardenberg, M. Shachak, and Y. Zarmi. Vegetation patterns along a rainfall gradient. Chaos Solitons Fractals, 19(2):367-376, 2004. URL: http://dx.doi.org/10.1016/S0960-0779(03) 00049-3

[68] E.T. Mitchard and C.M. Flintrop. Woody encroachment and forest degradation in sub-saharan africa's woodlands and savannas 1982-2006. Philos. Trans. R. Soc. Lond. B. Biol. Sci., 368, 2013. URL: https: //doi.org/10.1098/rstb.2012.0406

[69] E.T.A. Mitchard, S.S. Saatchi, S.L. Lewis, T.R. Feldpausch, I.H. Woodhouse, B. Sonké, C. Rowland, and P. Meir. Measuring biomass changes due to woody encroachment and deforestation/degradation in a forestsavanna boundary region of central africa using multitemporal 1-band radar backscatter. Remote Sensing of Environment, 115(11):2861 - 2873, 2011. DESDynI VEG-3D Special Issue. URL: https://doi.org/10.1016/ j.rse.2010.02.022

[70] A. Moustakas, W. E. Kunin, T. C. Cameron, and M. Sankaran. Facilitation or competition ? Tree effects on grass biomass across a precipitation gradient. PLoS One, 8:e57025, 2013. URL: http://dx.doi.org/10.1371/ journal.pone.0057025

[71] P. Narbel. Qualitative and Quantitative Cellular Automata from Differential Equations, pages 112-121. Cellular Automata. ACRI 2006. Lecture Notes in Computer Science, vol 4173. Springer, Berlin, Heidelberg, 2006. URL: https://doi.org/10.1007/11861201_16.

[72] I. Oliveras and Y. Malhi. Many shades of green: the dynamic tropical forest-savannah transition zones. Phil. Trans. R. Soc. B, 371:20150308, 2016. URL: http://dx.doi.org/10.1098/rstb.2015.0308

[73] S. Omohundro. Modelling cellular automata with 
partial differential equations. Physica D: Nonlinear Phenomena, 10(1):128 - 134, 1984. URL: https: //doi.org/10.1016/0167-2789(84)90255-0

[74] R. Oslisly, L. White, I. Bentaleb, C. Favier, M. Fontugne, J-F. Gillet, and D. Sebag. Climatic and cultural changes in the west congo basin forests over the past 5000 years. Phil. Trans. R. Soc. B, 368:20120304, 2013. URL: http://dx.doi.org/10.1098/ rstb.2012.0304

[75] M. Sankaran, N.P. Hanan, R.J. Scholes, J. Ratnam, DJ. Augustine, B.S. Cade, J. Gignoux, S.I. Higgins, X. LeRoux, F. Ludwig, J. Ardo, F. Banyikwa, A. Bronn, G. Bucini, K.K. Caylor, M.B. Coughenour, A. Diouf, W. Ekaya, C.J. Feral, E.C. February, P.G.H. Frost, P. Hiernaux, H. Hrabar, K.L. Metzger, H.H.T. Prins, S. Ringrose, W. Sea, J. Tews, J. Worden, and N. Zambatis. Determinants of woody coverin african savannas. Nature, 438:846-849, 2005. URL: http: //dx.doi.org/10.1038/nature04070

[76] G. Sarmiento. The Ecology of Neotropical Savannas. Harvard Univerity Press, Cambridge, MA, 1984.

[77] S. Scheiter and S.I. Higgins. Partitioning of root and shoot competition and the stability of savannas. Am. Nat., 179:587-601, 2007. URL: http://dx.doi.org/10. $1086 / 521317$

[78] R.J. Scholes. Convex relationships in ecosystems containing mixtures of trees and grass. Environnemental and Ressource Economics, 26:559-574, 2003. URL: http://dx.doi.org/10.1023/B:EARE.0000007349. 67564.b3

[79] R.J. Scholes and S.R. Archer. Tree-grass interactions in savannas. Annu. Rev. Ecol. Syst., 28:517-544, 1997. URL: http://dx.doi.org/10.1146/annurev.ecolsys. 28.1.517.

[80] R.J. Scholes and B. Walker. An African Savanna: Synthesis of the Nylsvley Study. Cambridge University Press, Cambridge, 1993.

[81] J.A. Sherratt. An analysis of vegetation stripe formation in semi-arid landscapes. J. Math. Biol., 51:183-197, 2005. URL: http://dx.doi.org/10.1007/ s00285-005-0319-5.

[82] C. Skarpe. Shrub layer dynamics under different herbivore densities in an arid savanna, botswana. Journal of Applied Ecology, 27(3):873-885, 1990. URL: https: //doi.org/10.2307/2404383

[83] A.C. Staver, S. Archibald, and S. Levin. Tree cover in sub-saharan Africa: Rainfall and fire constrain forest and savanna as alternative stable states. Ecology, 92(5):1063-1072, 2011. URL: http://dx.doi.org/10. 1890/10-1684.1.

[84] A.C. Staver and S. Levin. Integrating theoretical climate and fire effects on savanna and forest systems. Am. Nat., 180:14 pages, 2012. URL: http://dx.doi.org/ 10.1086/666648

[85] A.D. Synodinos, B. Tietjen, and F. Jeltsch. Facilitation in drylands: Modeling a neglected driver of savanna dynamics. Ecol. Modell., 304:11-21, 2015. URL: http: //dx.doi.org/10.1016/j.ecolmodel.2015.02.015.

[86] A.D. Synodinos, B. Tietjen, D. Lohmann, and F. Jeltsch. The impact of inter-annual rainfall variability on african savannas changes with mean rainfall. Journal of Theoretical Biology, 437:92 - 100, 2018. URL: https://doi.org/10.1016/j.jtbi.2017.10.019

[87] A. Tchuinté Tamen. Study of a Generic Mathematical Model of Forest-Savanna Interactions: Case of Cameroon. PhD thesis, University of Yaouné I, 2017.

[88] A. Tchuinté Tamen, P. Couteron, and Y. Dumont. Effect of fire frequency and rainfall on tree-grass dynamics: Capturing the forest-savanna distributions at biogeographic scale. ArXiv preprint, arXiv:1802.05986, 2018. URL: https://arxiv.org/abs/1802.05986

[89] A. Tchuinté Tamen, Y. Dumont, J. J. Tewa, S. Bowong, and P. Couteron. Tree-grass interaction dynamics and pulsed fires: mathematical and numerical studies. Appl. Math. Mod., 40(11-12):6165-6197, June 2016. URL: https://doi.org/10.1016/j.apm.2016.01.019.

[90] A. Tchuinté Tamen, Y. Dumont, J. J. Tewa, S. Bowong, and P. Couteron. A minimalistic model of tree-grass interactions using impulsive differential equations and non-linear feedback functions of grass biomass onto fire-induced tree mortality. Math. Comput. Simul, 133:265-297, March 2017a. URL: http://dx.doi.org/ 10.1016/j.matcom.2016.03.008

[91] A. Tchuinté Tamen, J. J. Tewa, P. Couteron, S. Bowong, and Y. Dumont. A generic modeling of fire impact in a tree-grass savanna model. Biomath, 3:1407191, 2014. URL: http://dx.doi.org/10.11145/j. biomath.2014.07.191

[92] J.J. Tewa, I.V. Yatat Djeumen, and S. Bowong. Predator-prey model with holling response function of type ii and sis infectious disease. Appl. Math. Modell., 37(7):4825 - 4841, 2013. URL: https://doi.org/10. 1016/j.apm.2012.10.003

[93] K. Thonicke, S. Venevsky, S. Sitch, and W. Cramer. The role of fire disturbance for global vegetation dynamics: coupling fire into a dynamic global vegetation model. Global Ecol. Biogeogr., 10(6):661-677, 2001. URL: https://doi.org/10.1046/j.1466-822X.2001. 00175.x.

[94] D. Tilman. Competition and biodiversity in spatially structured habitats. Ecology, 75(1):2-16, 1994. URL: https://www.jstor.org/stable/1939377

[95] M. Torello-Raventos, T.R. Feldpausch, K. Veenendaal, F. Schrodt, G. Saiz, T.F. Domingues, G. Djagbletey, A. Ford, J. Kemp, B.S. Marimon, B.H. Marimon, E. Lenza, J.A. Ratter, L. Maracahipes, D. Sasaki, B. Sonke, L. Zapfack, H. Taedoumg, D. Villarroel, M. Schwarz, C.A. Quesada, F. Yoko Ishida, G.B. Nardoto, K. Affum-Baffoe, L. Arroyo, D. Bowman, H. Compaore, K. Davies, A. Diallo, N.M. Fyllas, M. Gilpin, F. Hien, M. Johnson, T.J. Killeen, D. Metcalfe, H.S. Miranda, M. Steininger, J. Thomson, K. Sykora, E. Mougin, P. Hiernaux, M.I. Bird, J. Grace, 
S.L. Lewis, O.L. Phillips, and J. Lloyd. On the delineation of tropical vegetation types with an emphasis on forest/savanna transitions. Plant Ecology \& Diversity, 6(1):101-137, 2013. URL: https://doi.org/ 10.1080/17550874.2012.762812

[96] J.D. Touboul, C. Staver, and S.A. Levin. On the complex dynamics of savanna landscapes. Proceedings of the National Academy of Sciences, 2018. URL: https://doi.org/10.1073/pnas.1712356115

[97] W.S.W. Trollope. Fire in savanna. In P. de V. Booysen and N.M. Tainton, editors, Ecological Effects of Fire in South African Ecosystems, pages 149-175. SpringerVerlag, Berlin-Heidelberg-New York-Tokyo, 1984.

[98] W.S.W. Trollope. Personal perspectives on commercial versus communal african fire paradigms when using fire to manage rangelands for domestic livestock and wildlife in southern and east african ecosystems. Fire Ecology, 7(1):57-73, 2011. URL: https://doi.org/10. 4996/fireecology.0701057.

[99] W.S.W. Trollope and L.A. Trollope. Fire in african savanna and other grazing ecosystems. paper presented at the seminar on 'forest fire and global change' held in shshenkoye in the russian federation. 4-10 August 1996.

[100] W.S.W. Trollope and L.A. Trollope. Fire effects and management in african grasslands and savannas. Range and Animal Sci. Resour. Manag., 2:121145, 2010. URL: www.eolss.net/sample-chapters/c10/ E5-35-18.pdf

[101] F. Van Langevelde, C. Van de Vijver, L. Kumar, J. Van de Koppel, N. De Rider, and J. Van Andel. Effects of fire and herbivory on the stability of savanna ecosystems. Ecology, 84(2):337-350, 2003. URL: http://dx.doi.org/10.1890/0012-9658(2003)084[0337: EOFAHO]2.0.CO;2

[102] B.W. Van Wilgen, N. Govender, H.C. Biggs, D. Ntsala, and X.N. Funda. Response of savanna fire regimes to changing fire-management policies in a large african national park. Conserv. Biol., 18:1537-1540, 2004. URL: https://doi.org/10.1111/j.1523-1739.2004.00362. $\mathrm{X}$

[103] B. Walker, D. Ludwig, C.S. Holling, and R.M. Peterman. Stability of semi-arid savanna grazing systems. Journal of Ecology, 69(2):473-498, 1981. URL: https: //www.jstor.org/stable/pdf/2259679.pdf

[104] B. Walker and I. Noy-Meir. Aspects of the stability and resilience of savanna ecosystems. In B.J. Huntley and B.H. Walker, editors, Ecology of tropical savannas, pages 555-590. Springer-Verlag, Berlin, Germany, 1982.

[105] H. Walter. Ecology of tropical and subtropical vegetation. Oliver and Boyd, Edinburgh, UK, 1971.

[106] J.R. Weimar. Cellular automata for reaction-diffusion systems. Parallel Computing, 23(11):1699 - 1715, 1997. Cellular automata. URL: https://doi.org/10.1016/ S0167-8191(97)00081-1

[107] J.F. Weltzin and M.B. Coughenour. Savanna tree influence on understory vegetation and soil nutrients in northwestern Kenya. J. Veg. Sci., 1:325-334, 1990. URL: https://doi.org/10.2307/3235707

[108] S. Wolfram. Twenty problems in the theory of cellular automata. Physica Scripta, 1985(T9):170, 1985. URL: http://stacks.iop.org/1402-4896/1985/i=T9/a=029

[109] V. Yatat, P. Couteron, and Y. Dumont. Spatially explicit modelling of tree-grass interactions in fireprone savannas: a partial differential equations framework. Ecol. Compl., pages 290-313, 2018. URL: https://doi.org/10.1016/j.ecocom.2017.06.004

[110] V. Yatat, P. Couteron, J. J. Tewa, S. Bowong, and Y. Dumont. An impulsive modelling framework of fire occurrence in a size-structured model of treegrass interactions for savanna ecosystems. J. Math. Biol., 74(6):1425-1482, 2017. URL: http://dx.doi.org/ 10.1007/s00285-016-1060-y

[111] V. Yatat and Y. Dumont. FKPP equation with impulses on unbounded domain. In Mathematical Methods and Models in Biosciences, 2018. URL: http://dx.doi.org/ 10.11145/texts.2017.11.157.

[112] V. Yatat, Y. Dumont, J. J. Tewa, P. Couteron, and S. Bowong. Mathematical analysis of a size structured tree-grass competition model for savanna ecosystems. Biomath, 3:1404212, 2014. URL: http://dx.doi.org/10. 11145/j.biomath.2014.04.212

[113] I.V. Yatat Djeumen. Mathematical analysis of sizestructured tree-grass interactions models for savanna ecosystems. PhD thesis, University of Yaoundé I, 2018.

[114] J. Youta Happi. Arbres contre graminées: la lente invasion de la savane par la forêt au Centre-Cameroun. $\mathrm{PhD}$ thesis, Université de Paris IV, 1998.

[115] K. Yu and P. D'odorico. An eco-hydrological framework for grass displacement by woody plants in savannas. J. Geophys. Res. Biogeosci., 119:192-206, 2014. URL: http://dx.doi.org/10.1002/2013JG002577. 
I.V. Yatat Djeumen, A. Tchuinté Tamen, Y. Dumont, P. Couteron, A tribute to the use of minimalistic ...

\section{APPENDIX}

Table V: Parameter values used to obtain Figure 7.(a), page 17 From Accatino et al. (2010) [4] (here see model (3)).

\begin{tabular}{ccccccccc}
\hline$w_{1},-$ & $\varepsilon, \mathrm{yr}^{-1}$ & $c_{T}, \mathrm{yr}^{-1}$ & $c_{G}, \mathrm{yr}^{-1}$ & $\gamma_{T}, \mathrm{yr}^{-1}$ & $\gamma_{G}, \mathrm{yr}^{-1}$ & $\delta_{T}, \mathrm{yr}^{-1}$ & $\delta_{G}, \mathrm{yr}^{-1}$ & $\delta_{F},-$ \\
\hline 345 & 20 & 30 & 10 & 2 & 180 & 0.04 & 2.8 & 0.35 \\
\hline
\end{tabular}

Table VI: Parameter values used to get Figure 7.(b), page 17. From Tchuinté Tamen et al. (2018) [88] (here see model (6)).

\begin{tabular}{cccccc}
\hline$c_{G}$, t.ha $^{-1}$ & $c_{T}, \mathrm{t}_{\mathrm{ha}}{ }^{-1}$ & $b_{G}, \mathrm{~mm} . \mathrm{yr}^{-1}$ & $b_{T}, \mathrm{~mm} . \mathrm{yr}^{-1}$ & $a_{G}, \mathrm{yr}^{-1}$ & $a_{T}, \mathrm{yr}^{-1}$ \\
\hline 20 & 450 & 501 & 1192 & 0.0029 & 0.0045 \\
\hline$d_{G},-$ & $d_{T},-$ & $\gamma_{G}, \mathrm{yr}^{-1}$ & $\gamma_{T}, \mathrm{yr}^{-1}$ & $\delta_{G}, \mathrm{yr}^{-1}$ & $\delta_{T}, \mathrm{yr}^{-1}$ \\
\hline 14.73 & 106.7 & 2.5 & 1 & 0.01 & 0.1 \\
\hline$\lambda_{f G},-$ & $\lambda_{f T}^{m i n},-$ & $\lambda_{f T}^{\text {max }},-$ & $p, \mathrm{t}^{-1} \mathrm{ha}$ & $\alpha, \mathrm{t}^{-} \mathrm{ha}^{-1}$ & $\eta_{T G}, \mathrm{ha.t}^{-1} \mathrm{yr}^{-1}$ \\
\hline 0.3 & 0.05 & 0.7 & 0.01 & 1 & 0.01 \\
\hline
\end{tabular}

